\title{
Synthesis of $\alpha-\mathrm{CF}_{2}$-mannosides and their conversion to fluorinated pseudo-glycopeptides
}

\author{
NMR Spectra \\ Florent Poulain, Anne-Lise Serre, Jérôme Lalot, Eric Leclerc, Jean-Charles Quirion \\ Laboratoire d'Hétérochimie Organique, UMR 6014 CNRS, IRCOF, INSA et Université de Rouen, 1 rue Tesnière, 76821 Mont Saint-Aignan \\ Cedex, France \\ eric.leclerc@insa-rouen.fr
}

\begin{abstract}
${ }^{1} \mathrm{H} N M R,{ }^{13} \mathrm{C}$ NMR and ${ }^{19} \mathrm{~F}$ NMR spectra were recorded on a $300 \mathrm{Mhz}$ instrument and calibrated using residual undeuterated solvent as an internal reference and $\mathrm{CFCl}_{3}$ as an external reference. ${ }^{1} \mathrm{H},{ }^{13} \mathrm{C}, \mathrm{COSY}, \mathrm{HOESY}$ and $\mathrm{HMQC}$ spectra of compound 9 recorded on a $400 \mathrm{Mhz}$ instrument are also provided.
\end{abstract}

Compound 6
Compound $\beta-7$
Compound $\alpha-7$
Compound $\mathbf{8}$
Compound 9
Compound 12
Compound 13
Compound 14


${ }^{1} \mathrm{H}$ NMR $\left(\mathrm{CDCl}_{3}\right)$, compound 6

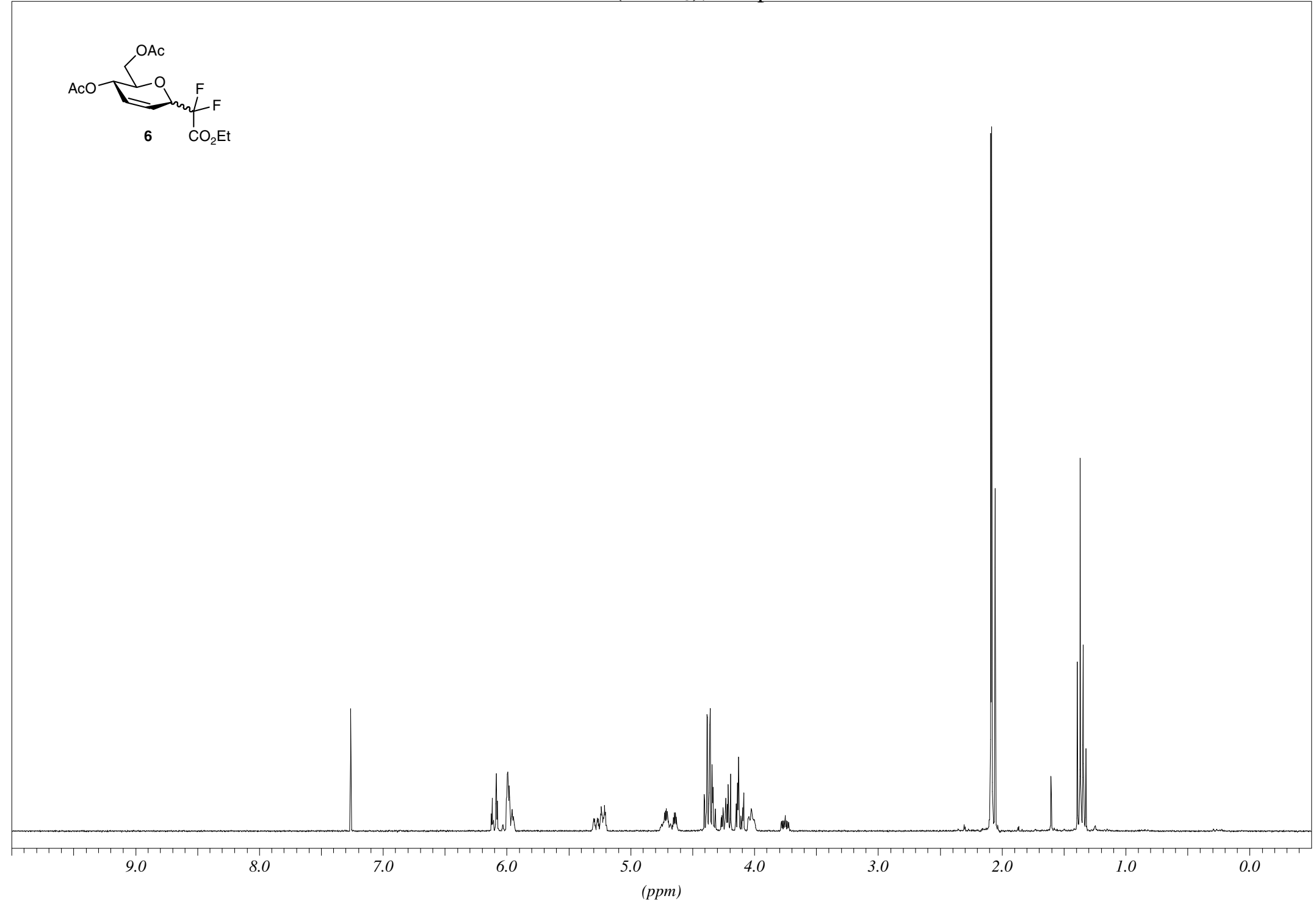


${ }^{19} \mathbf{F}$ NMR $\left(\mathrm{CDCl}_{3}\right)$, compound 6

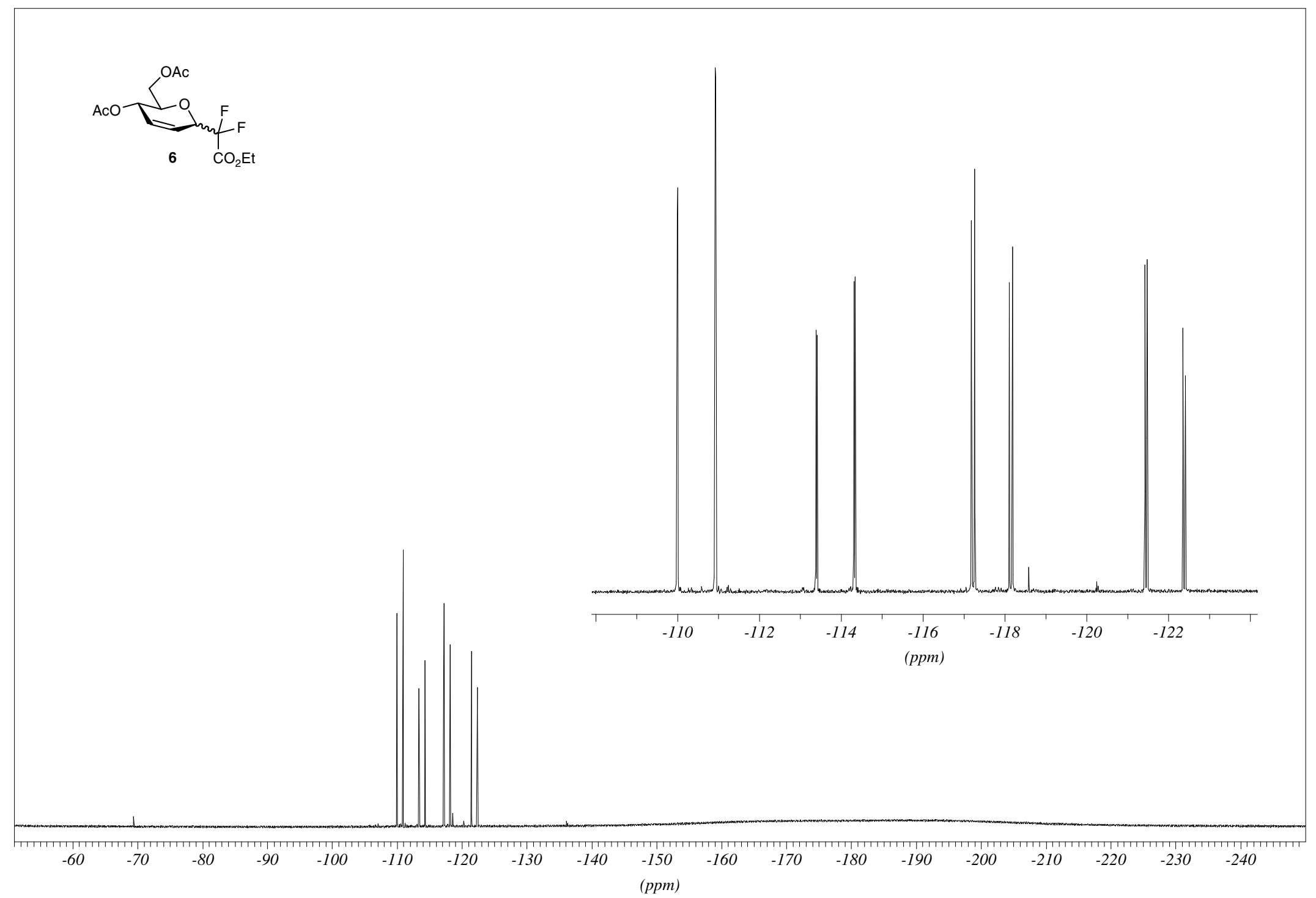


${ }^{1} \mathrm{H}$ NMR $\left(\mathrm{CDCl}_{3}\right)$, compound 6

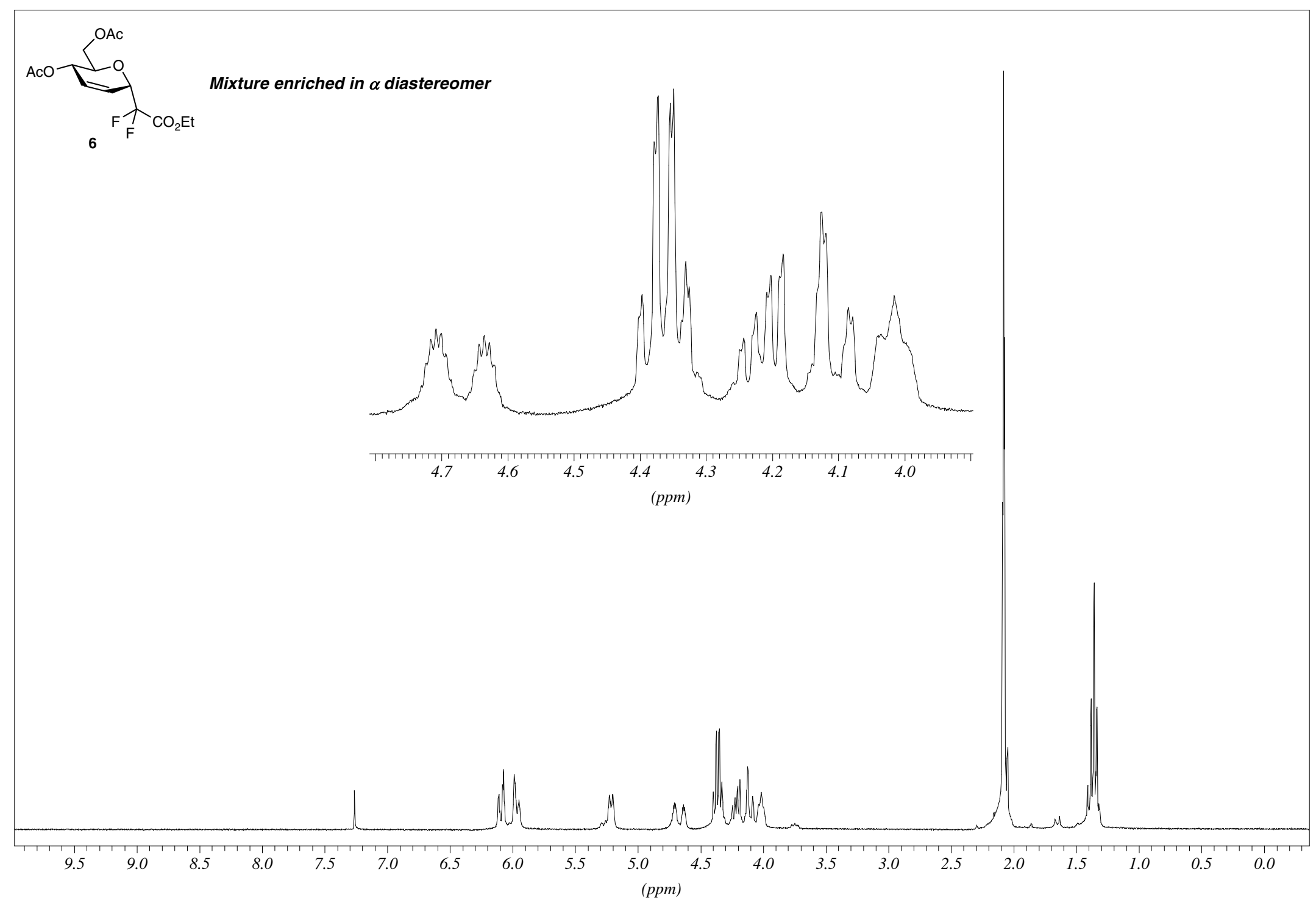


${ }^{19}$ F NMR $\left(\mathrm{CDCl}_{3}\right)$, compound 6

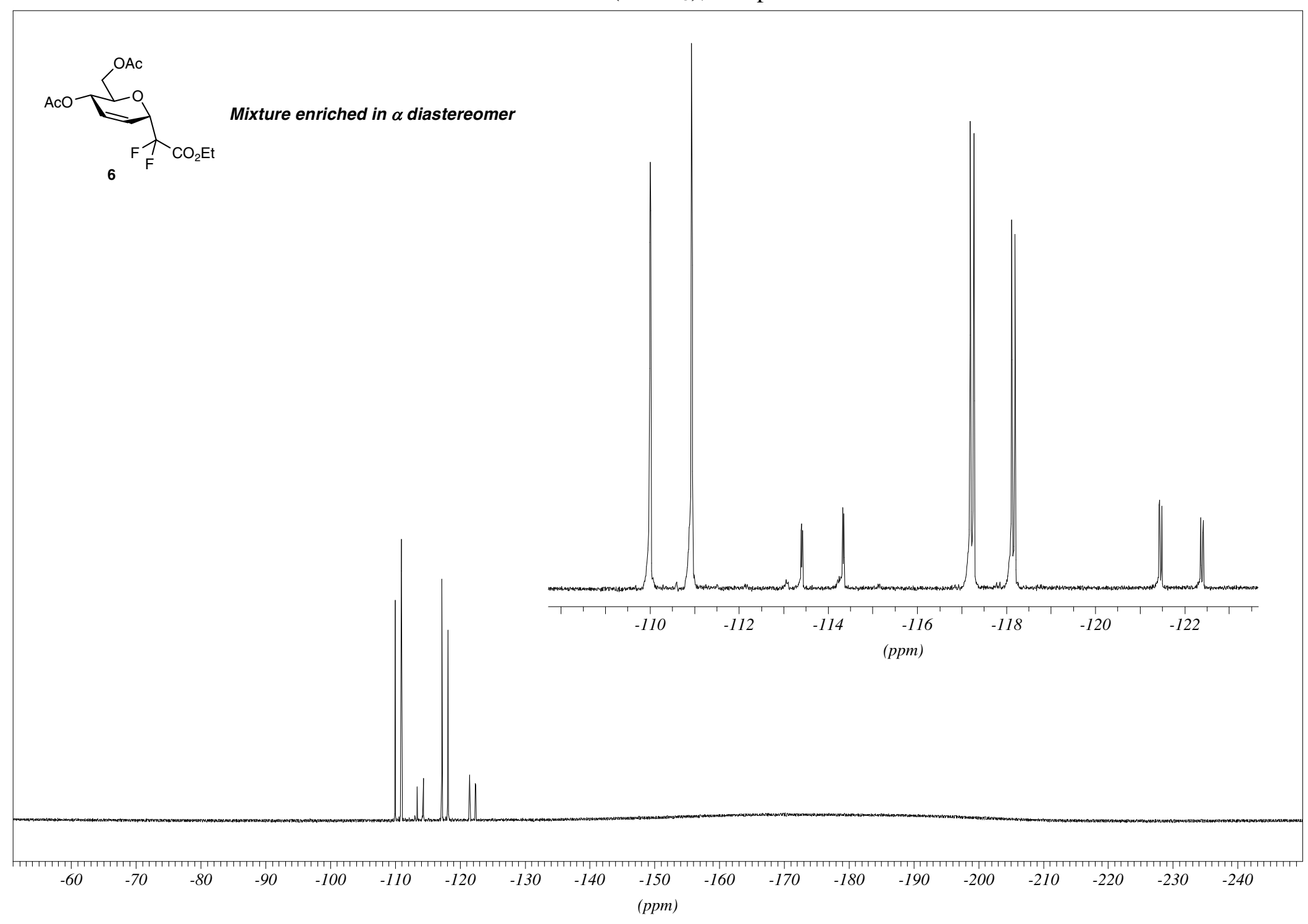


${ }^{13} \mathrm{C}$ NMR $\left(\mathrm{CDCl}_{3}\right)$, compound 6

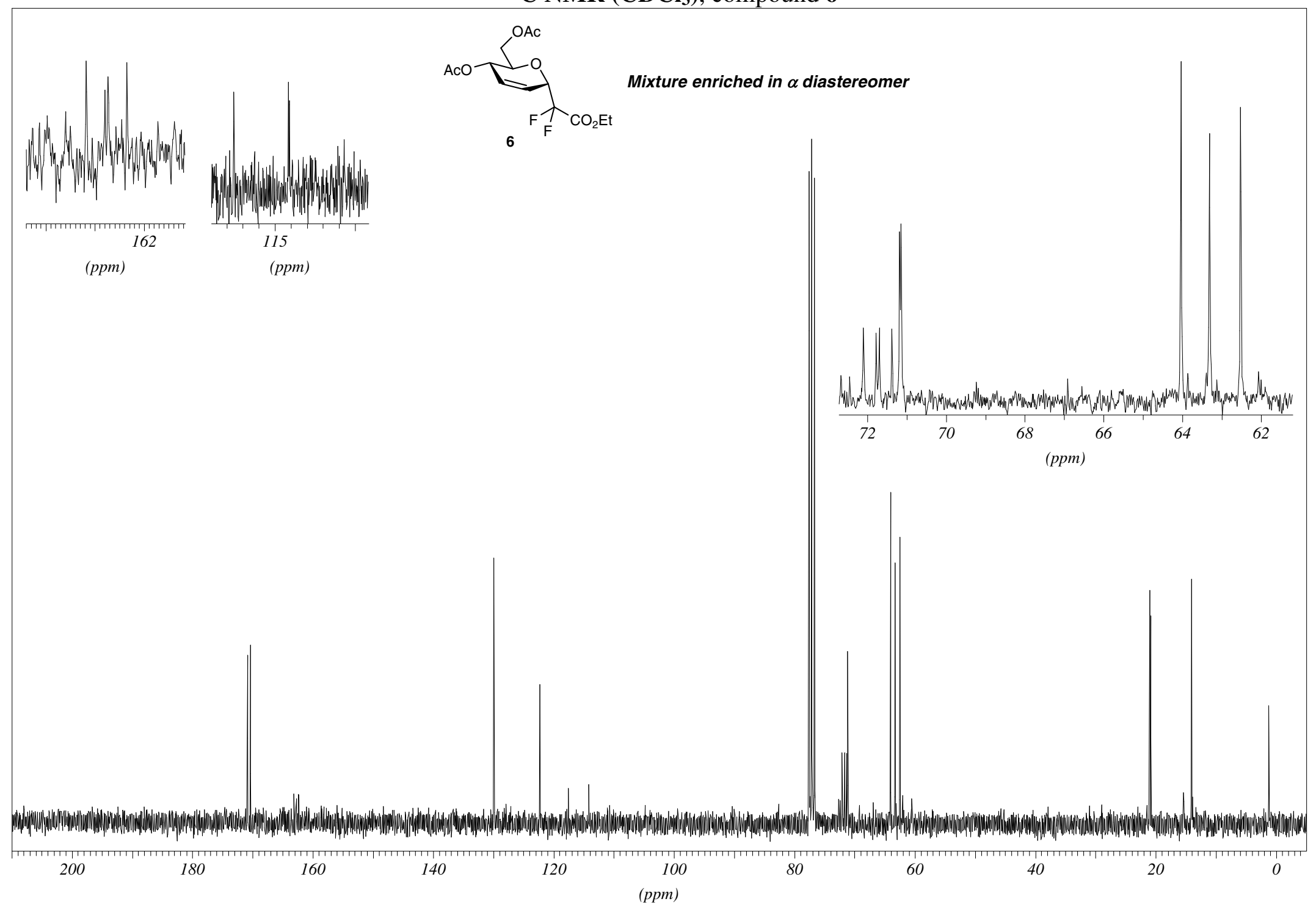

S18 
${ }^{1} \mathrm{H}$ NMR $\left(\mathrm{CDCl}_{3}\right)$, compound $\beta-7$

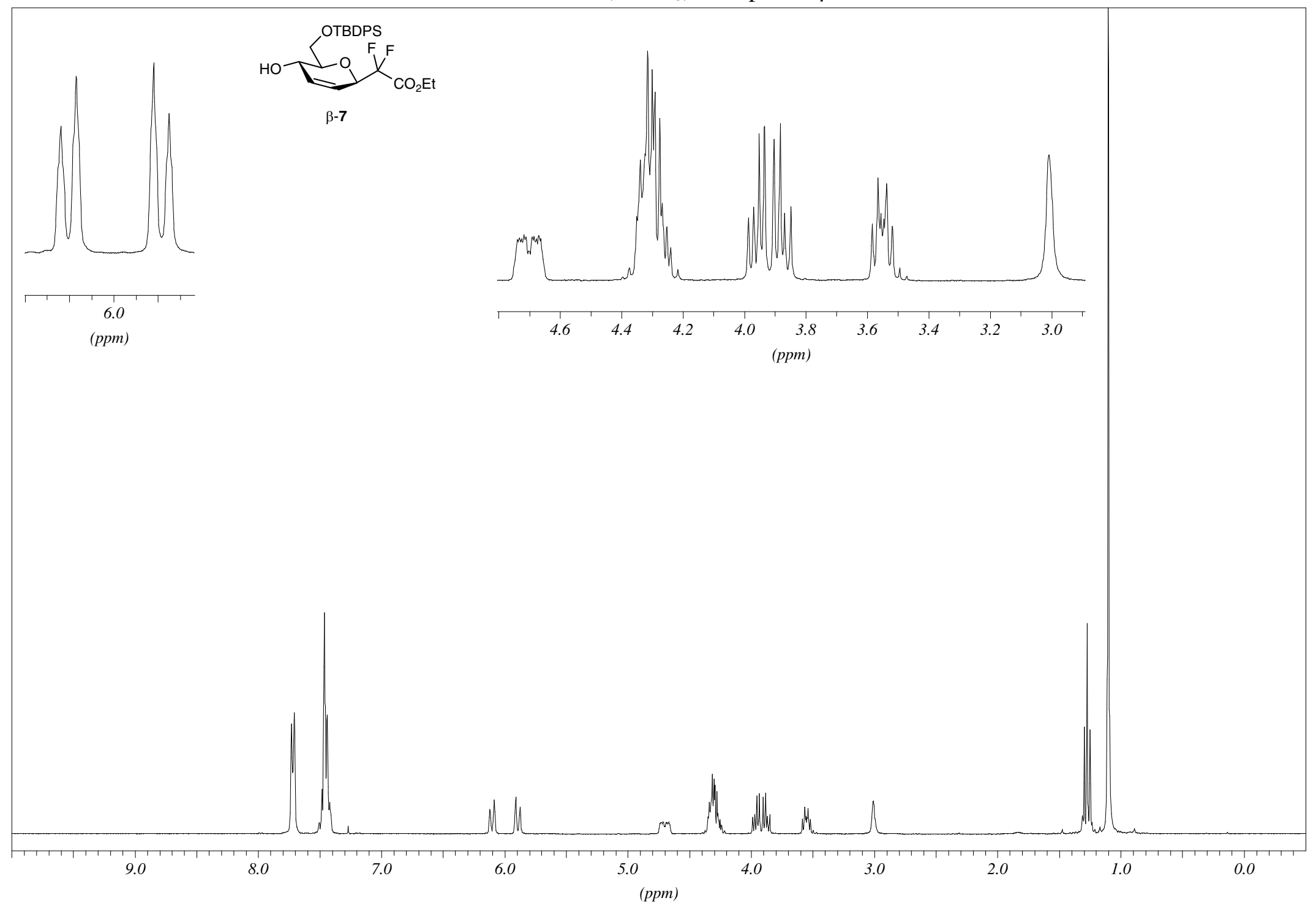




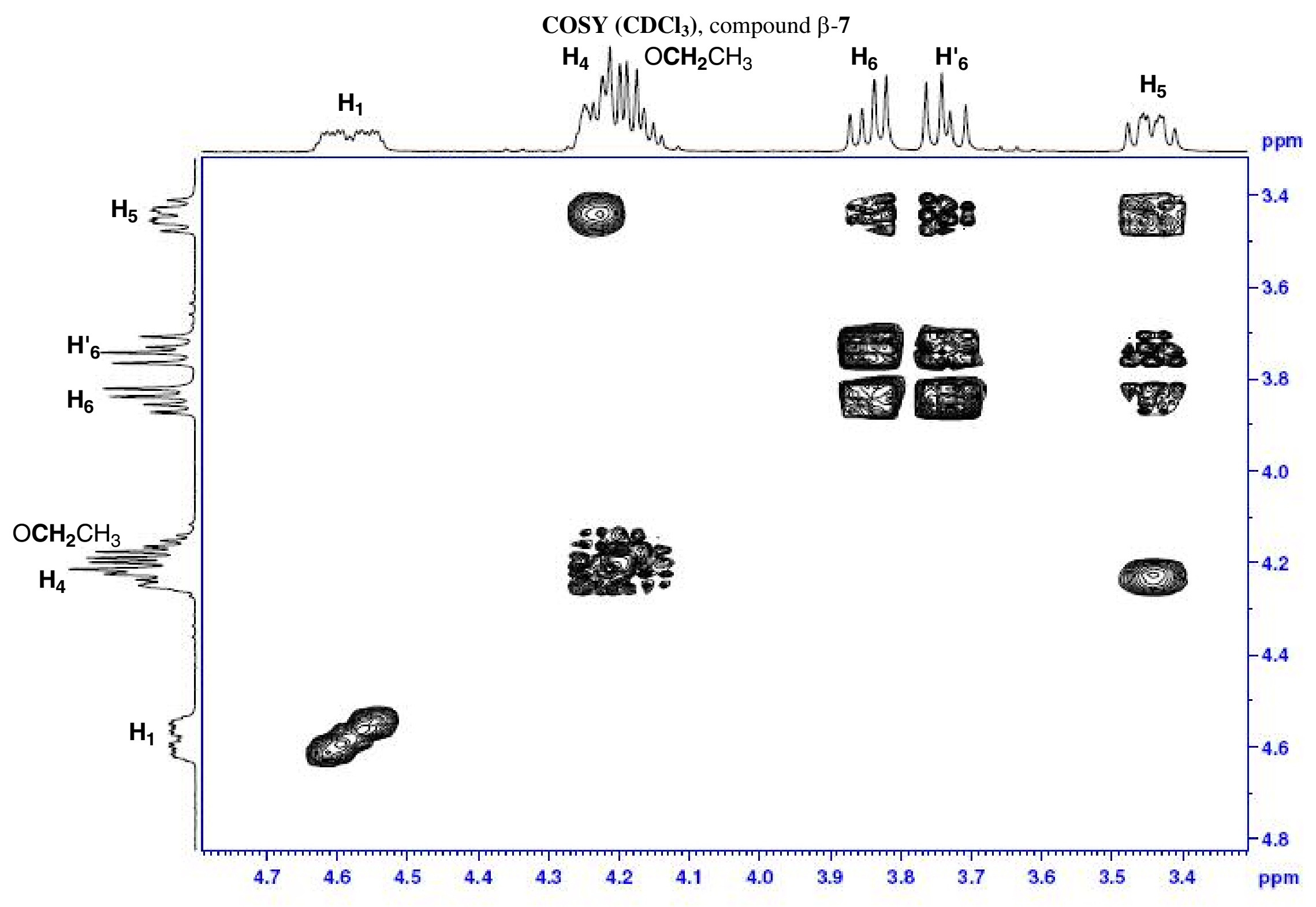




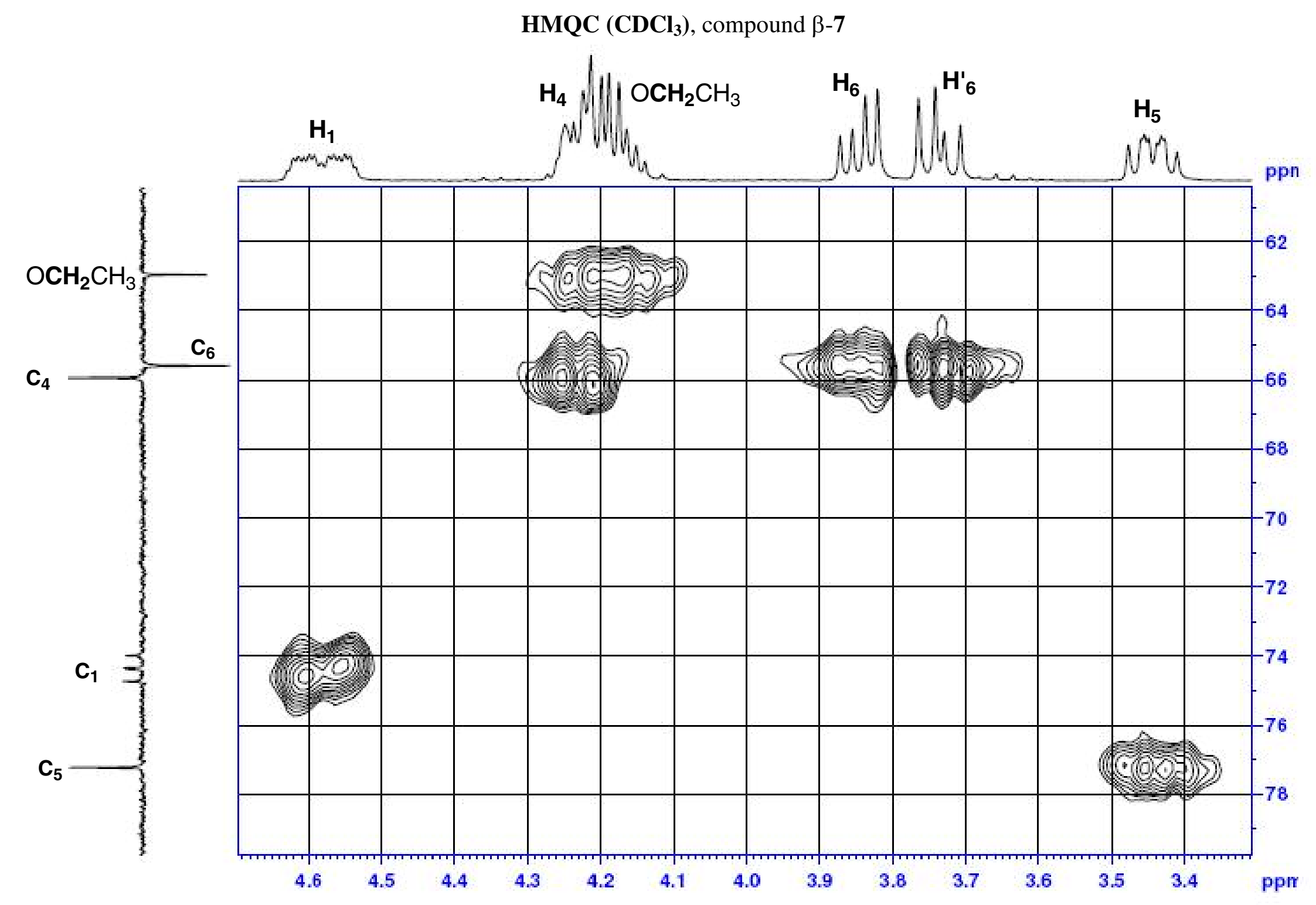




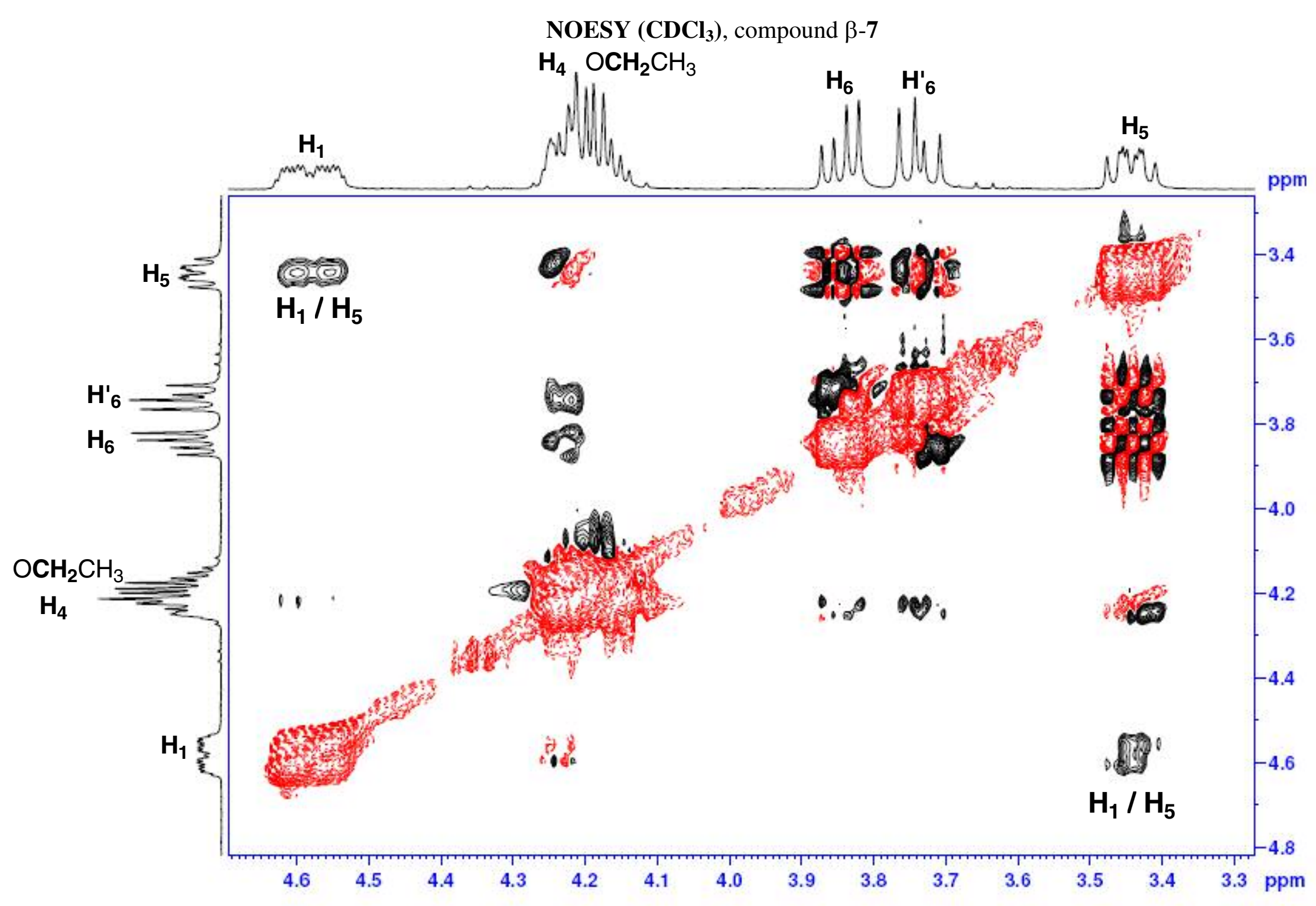


${ }^{19}$ F NMR $\left(\mathrm{CDCl}_{3}\right)$, compound $\beta-7$

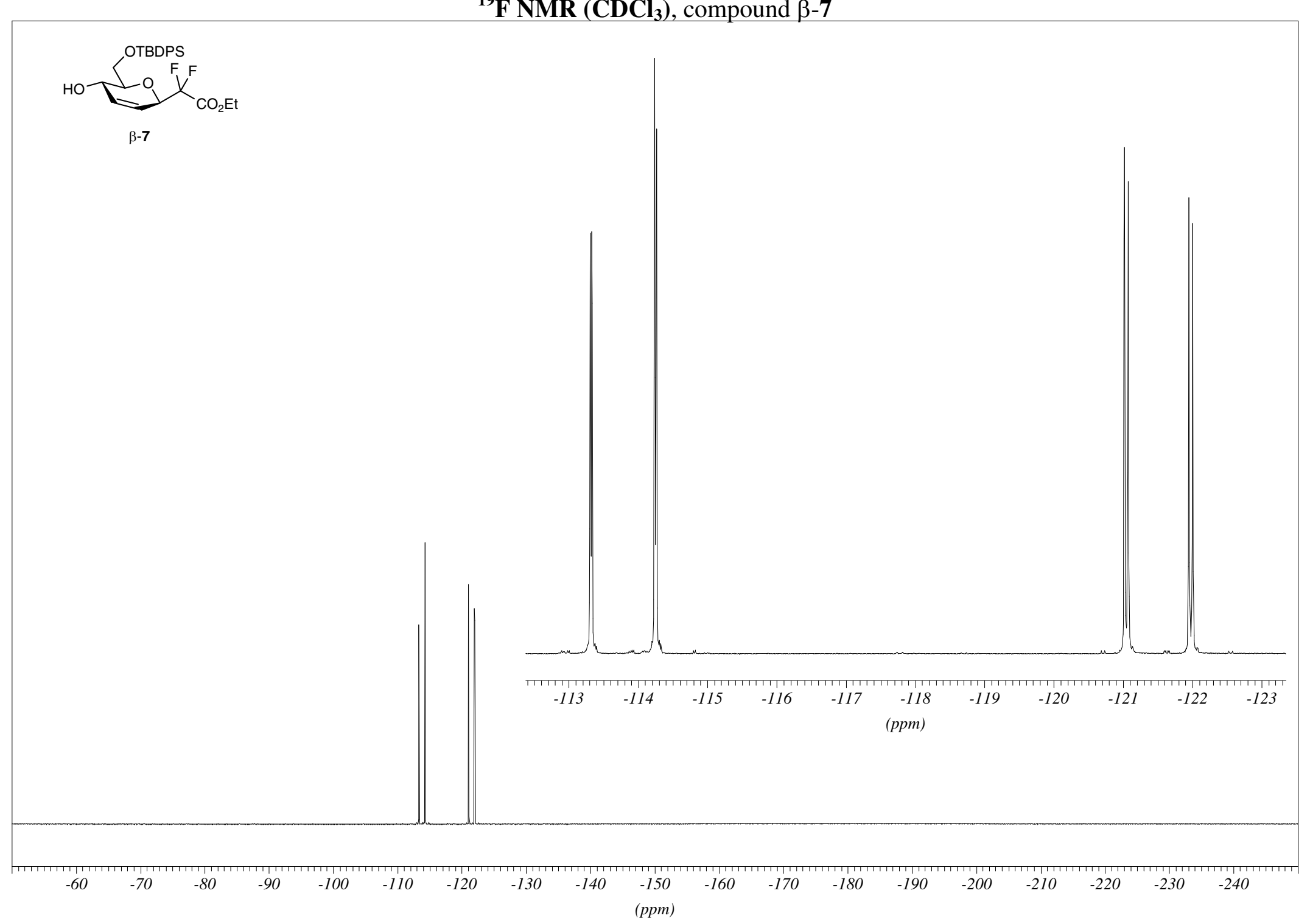


${ }^{13} \mathrm{C}$ NMR $\left(\mathrm{CDCl}_{3}\right)$, compound $\beta-7$

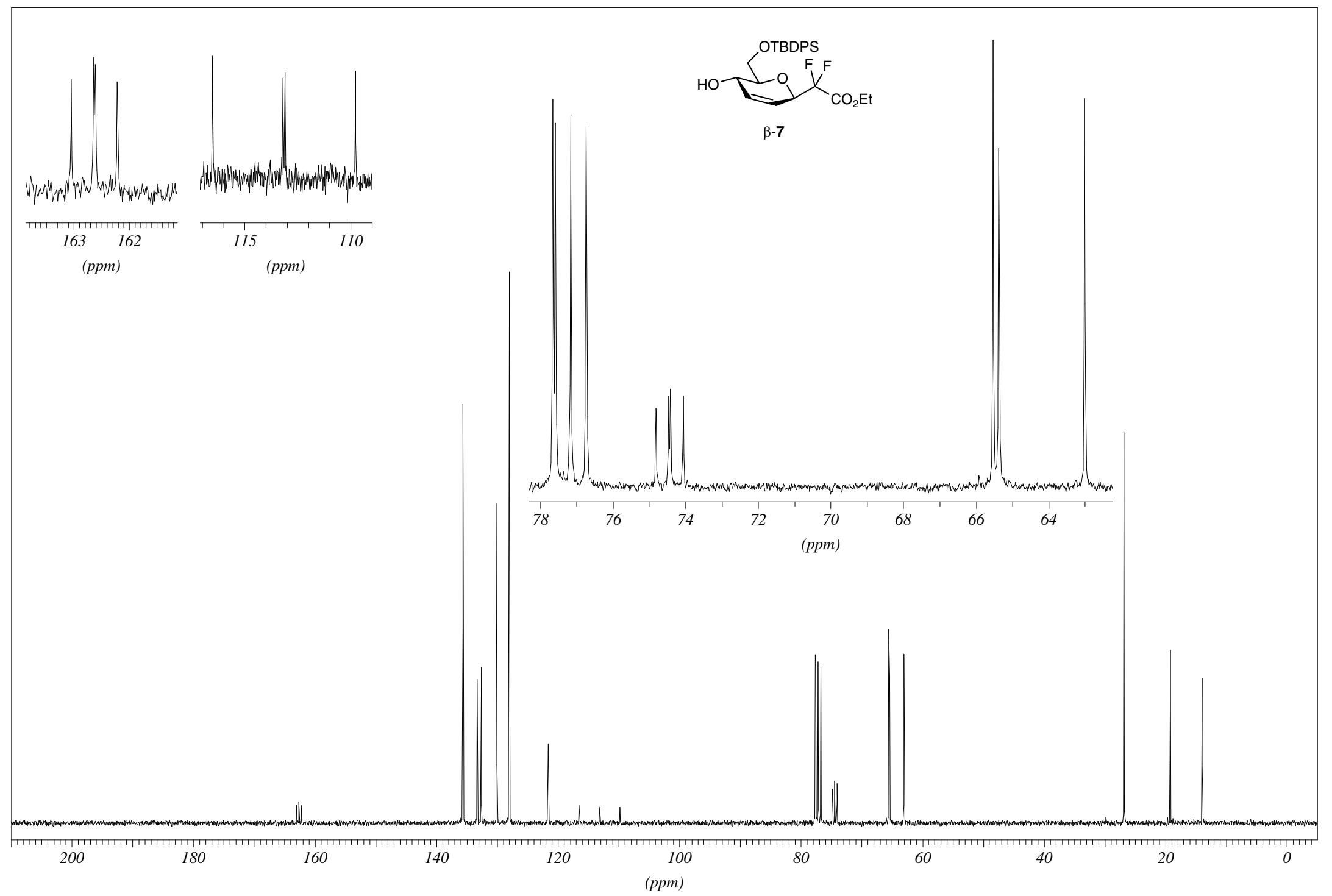


${ }^{13} \mathrm{C}$ NMR DEPT $135\left(\mathrm{CDCl}_{3}\right)$, compound $\beta-7$

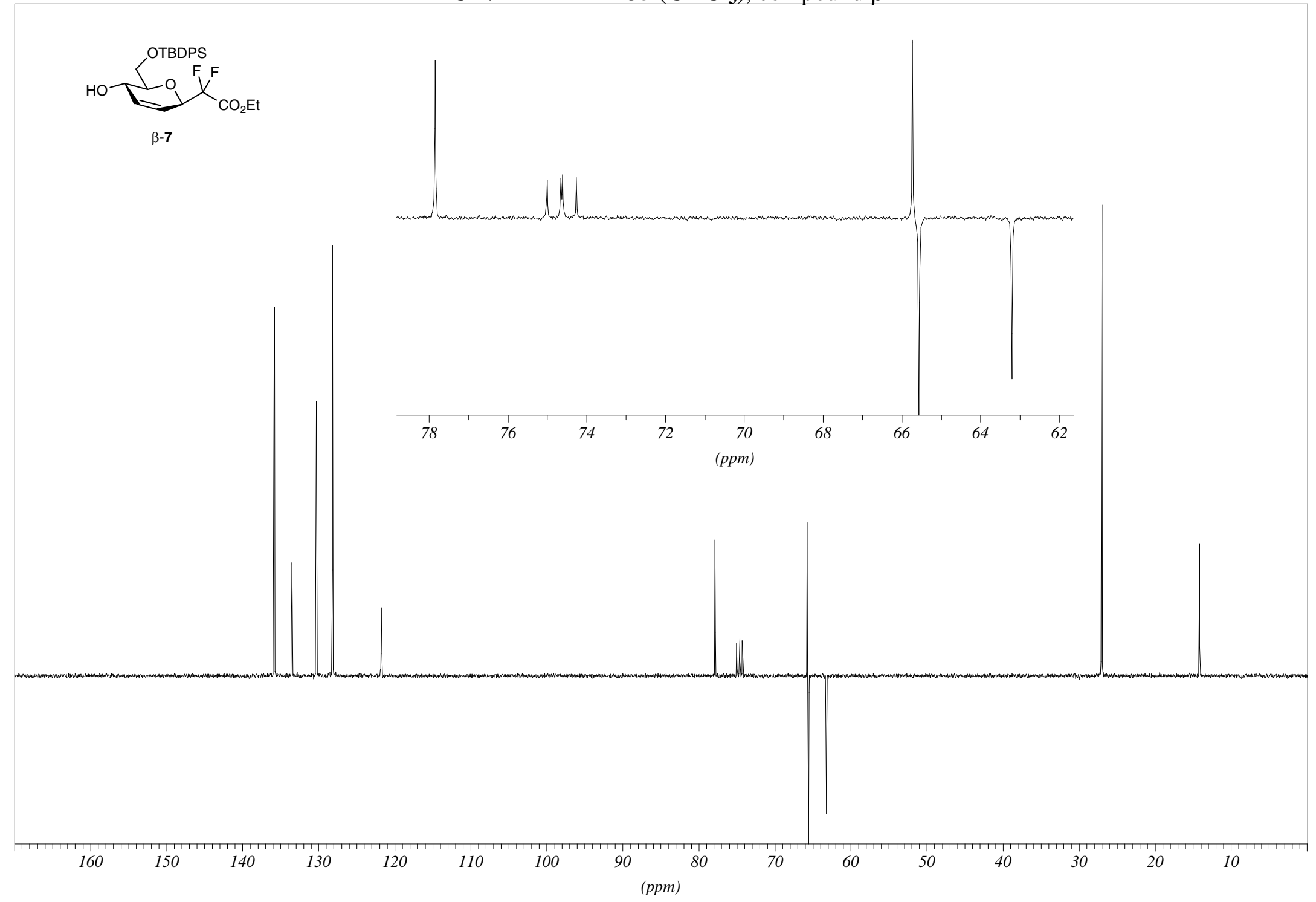


${ }^{1}$ H NMR $\left(\mathrm{CDCl}_{3}\right)$, compound $\alpha-7$

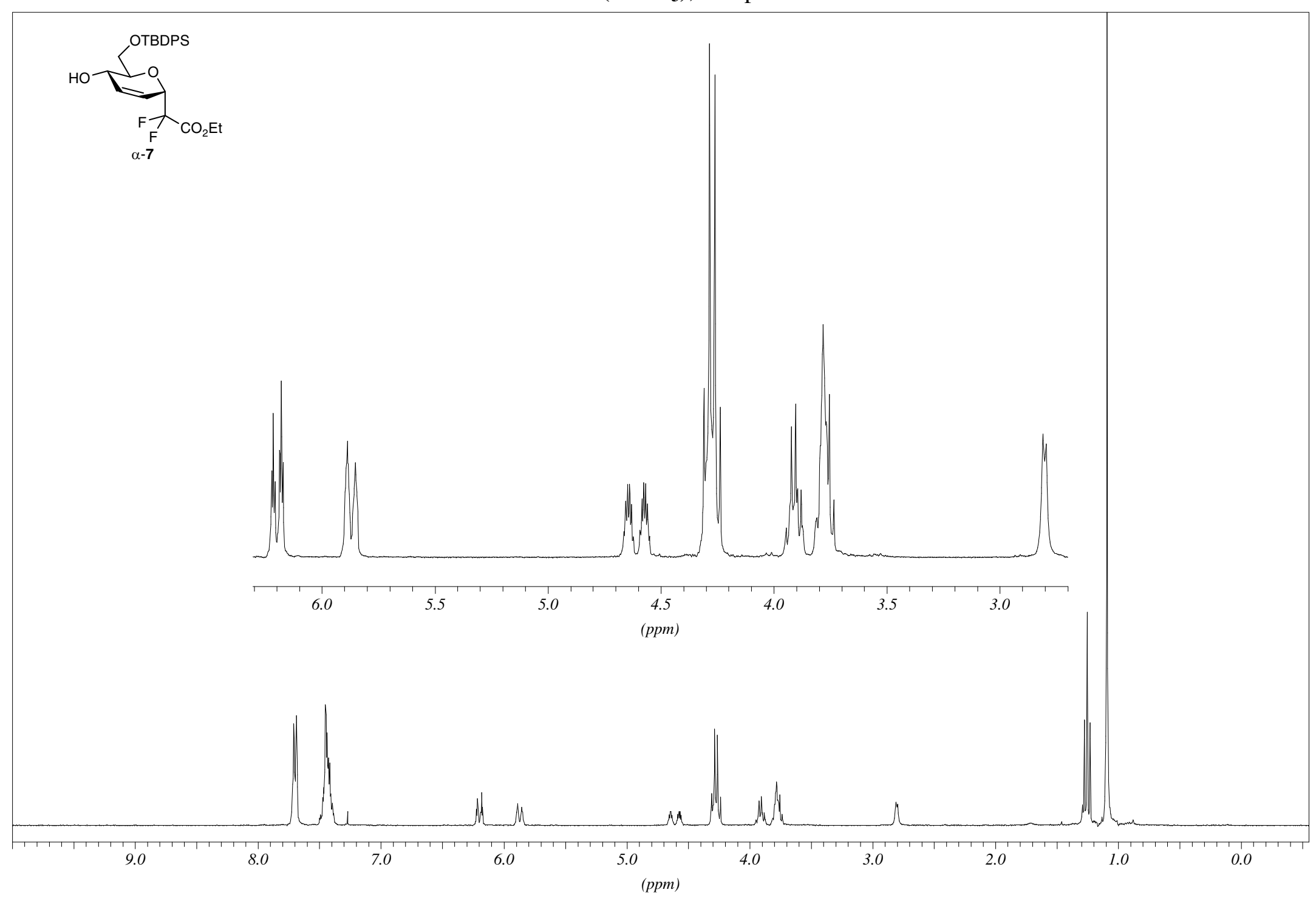


${ }^{19}$ F NMR $\left(\mathrm{CDCl}_{3}\right)$, compound $\alpha-7$

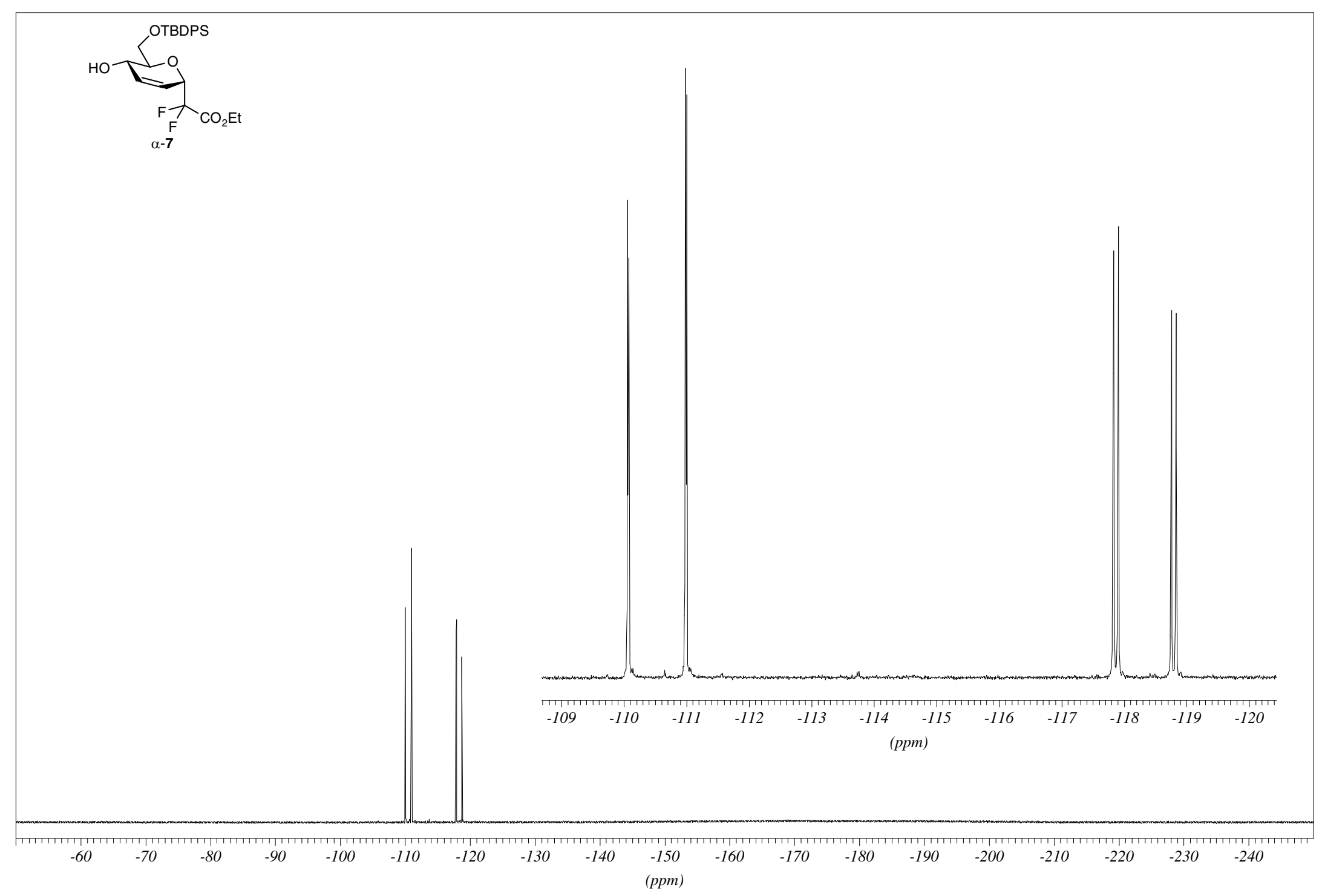


${ }^{13} \mathrm{C}$ NMR $\left(\mathrm{CDCl}_{3}\right)$, compound $\alpha-7$

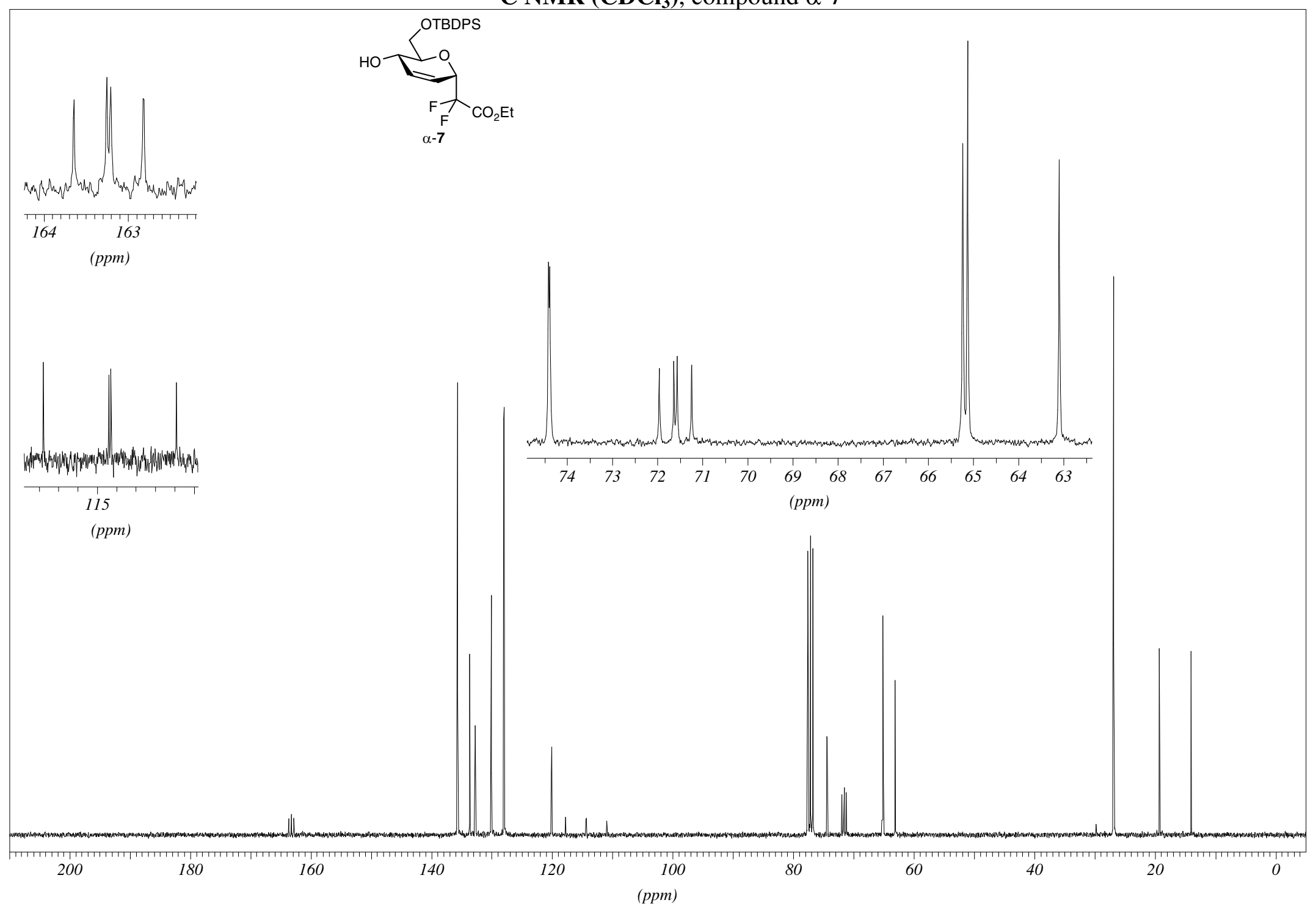


${ }^{1} \mathrm{H}$ NMR $\left(\mathrm{CDCl}_{3}\right)$, compound 8

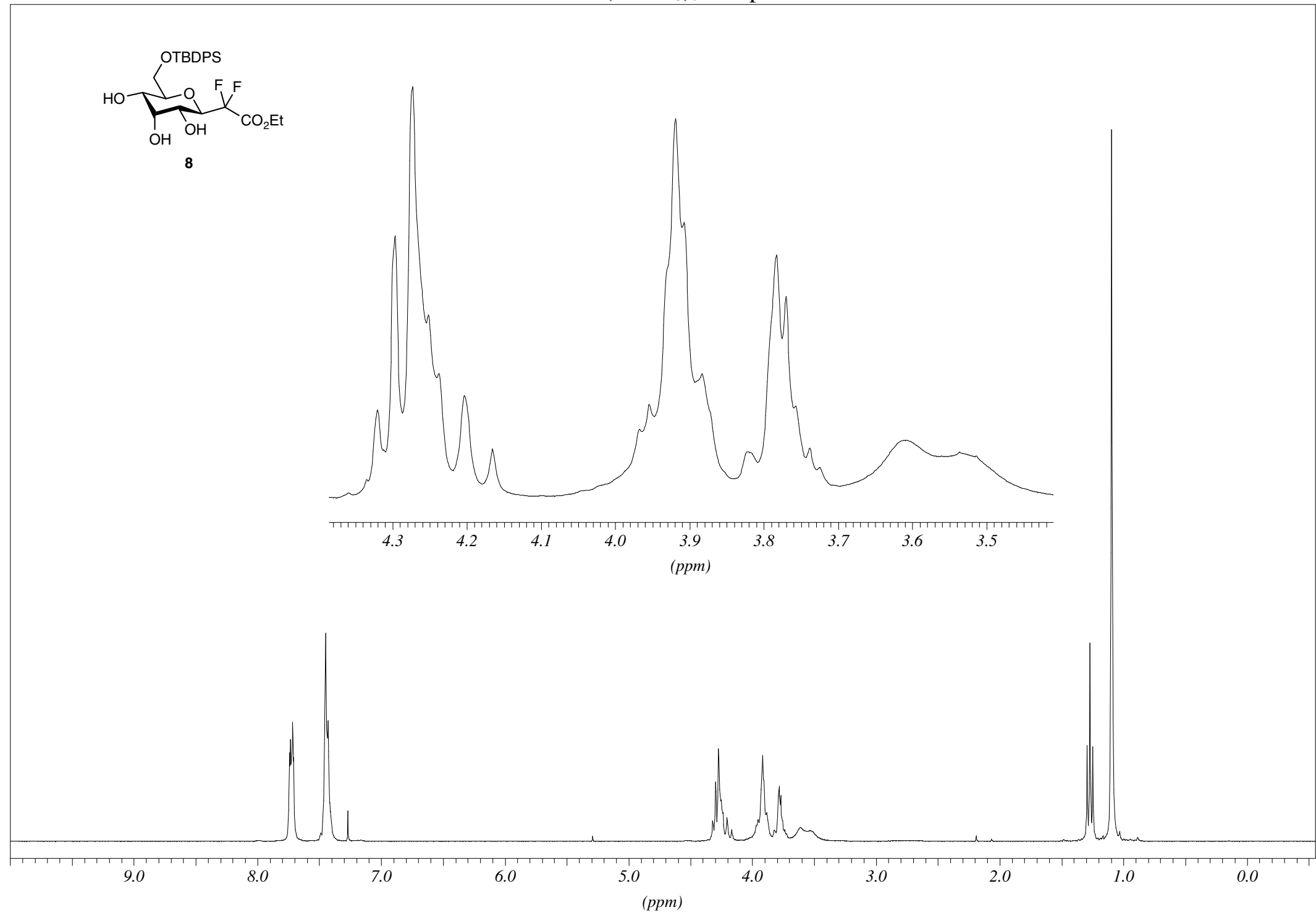


${ }^{19}$ F NMR $\left(\mathrm{CDCl}_{3}\right)$, compound 8

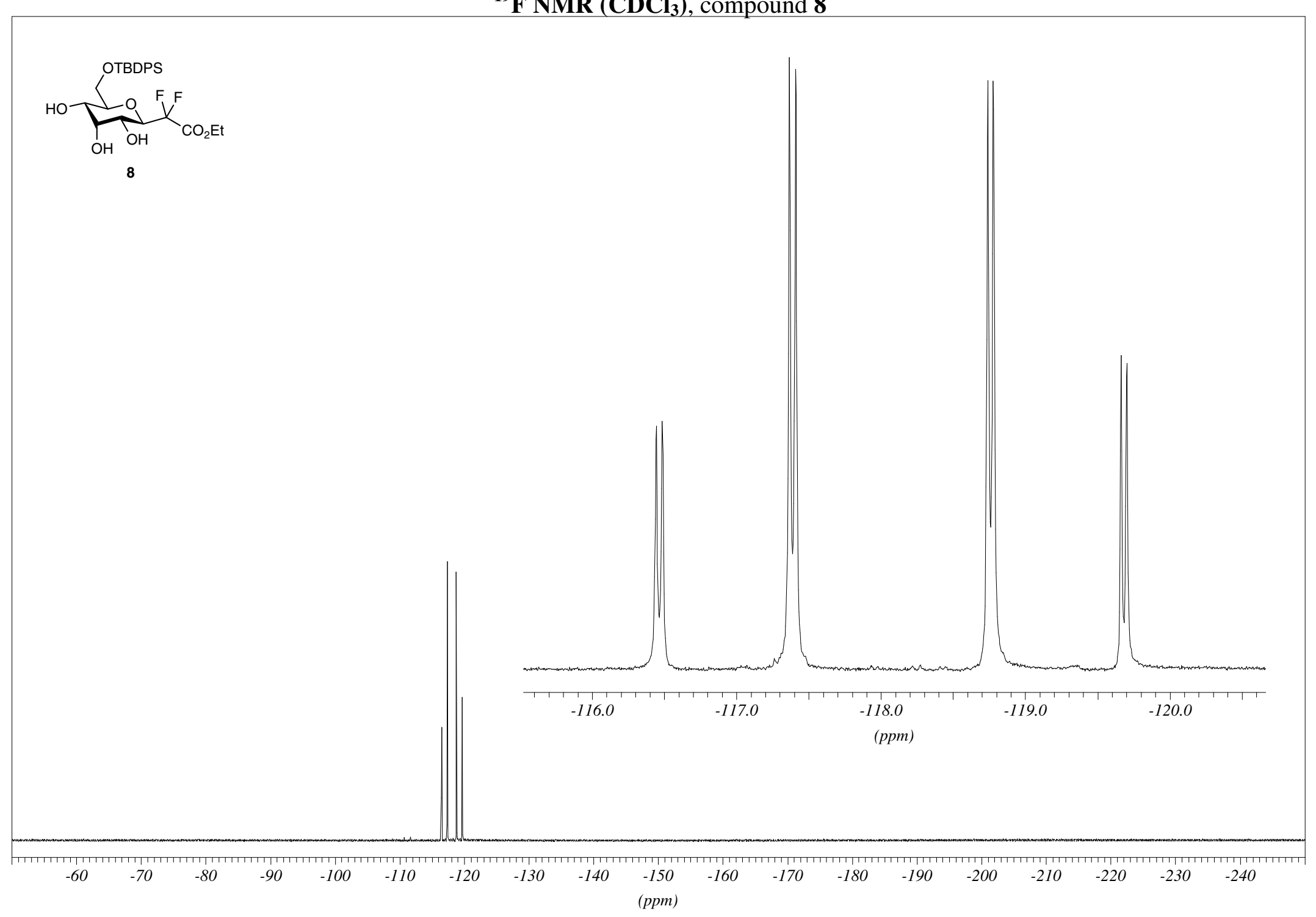




\section{${ }^{13} \mathrm{C}$ NMR $\left(\mathrm{CDCl}_{3}\right)$, compound 8}

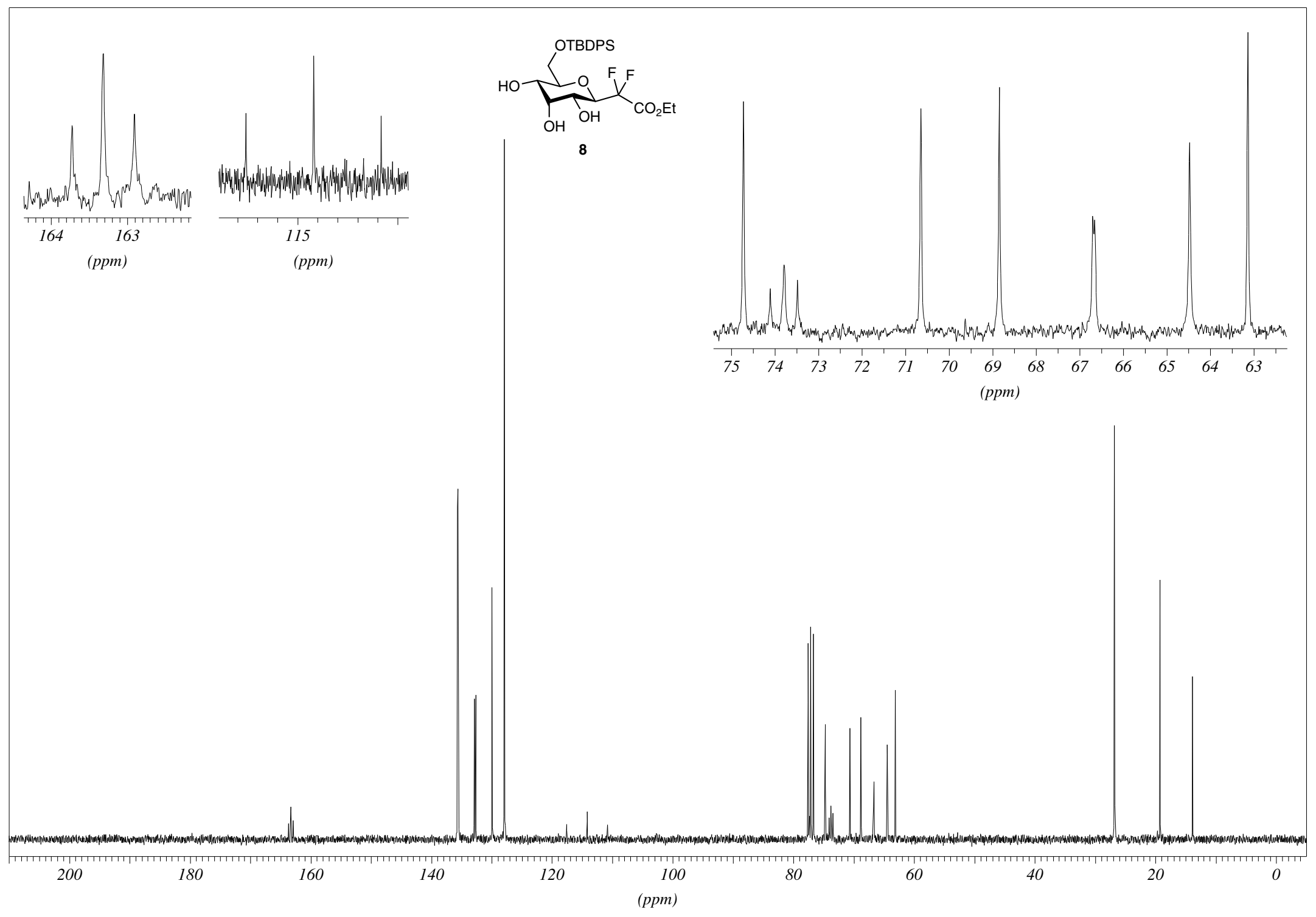


${ }^{13} \mathrm{C}$ NMR DEPT $135\left(\mathrm{CDCl}_{3}\right)$, compound 8

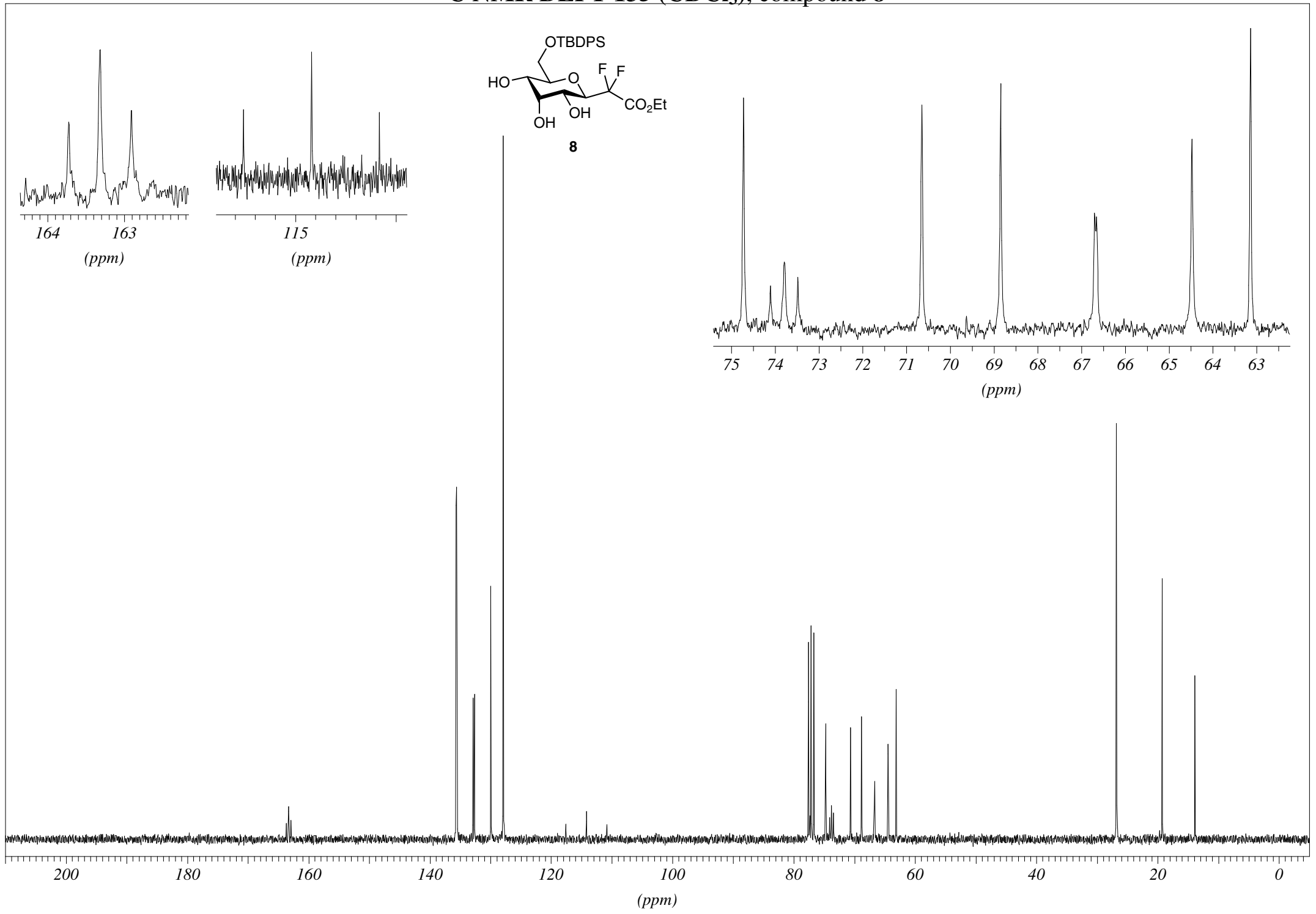


${ }^{1} \mathrm{H}$ NMR $\left(\mathrm{CDCl}_{3}\right)$, compound 9

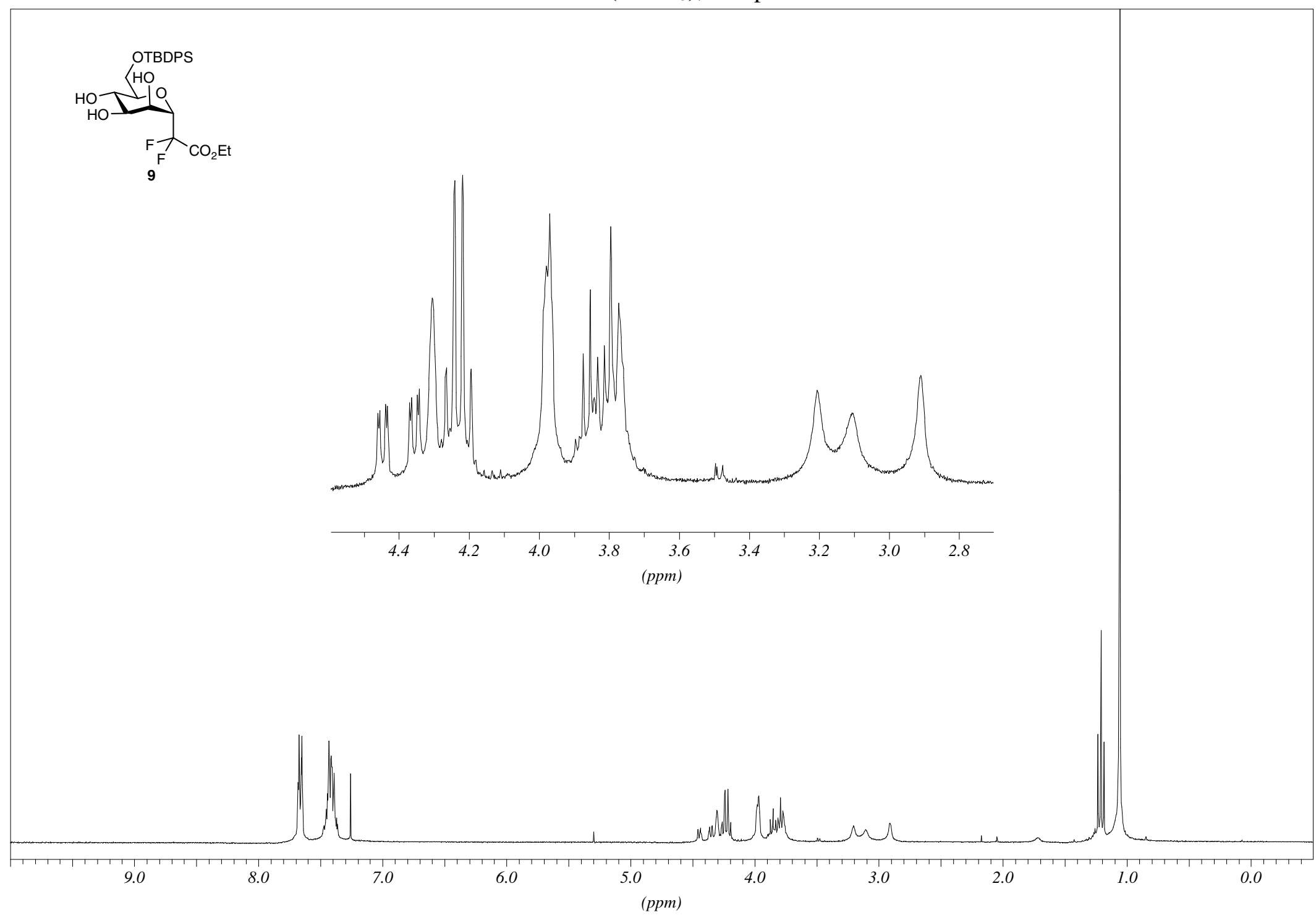


${ }^{19}$ F NMR $\left(\mathrm{CDCl}_{3}\right)$, compound 9

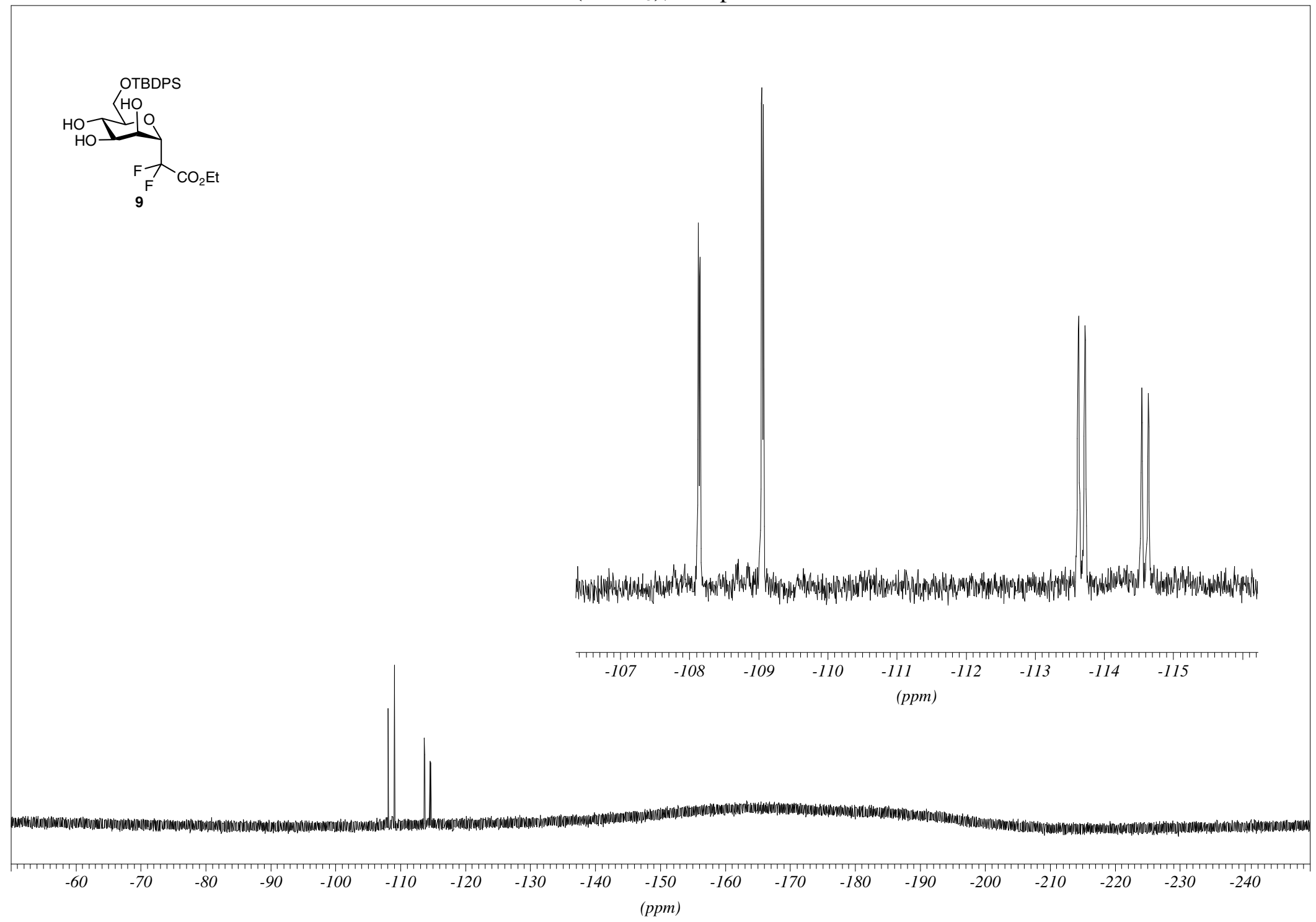

S34 


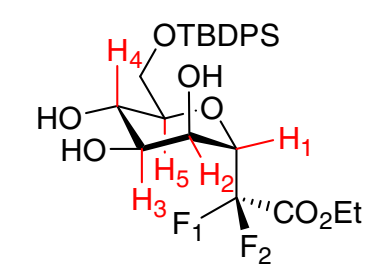

9

${ }^{1} \mathrm{H}$ spectrum decoupled from ${ }^{19} \mathrm{~F}$

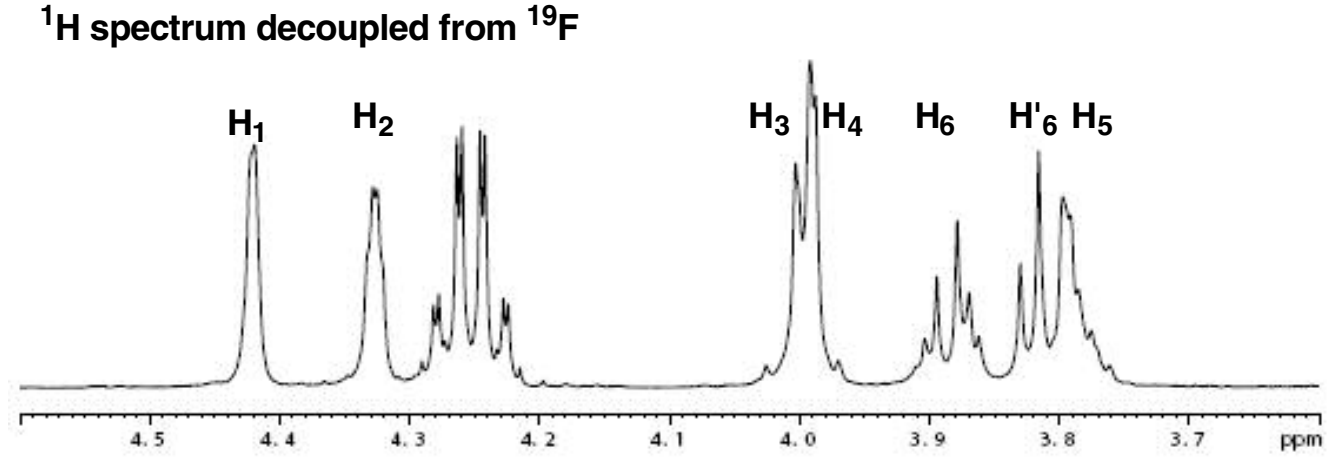

${ }^{1} \mathrm{H}$ spectrum coupled with ${ }^{19} \mathrm{~F}$

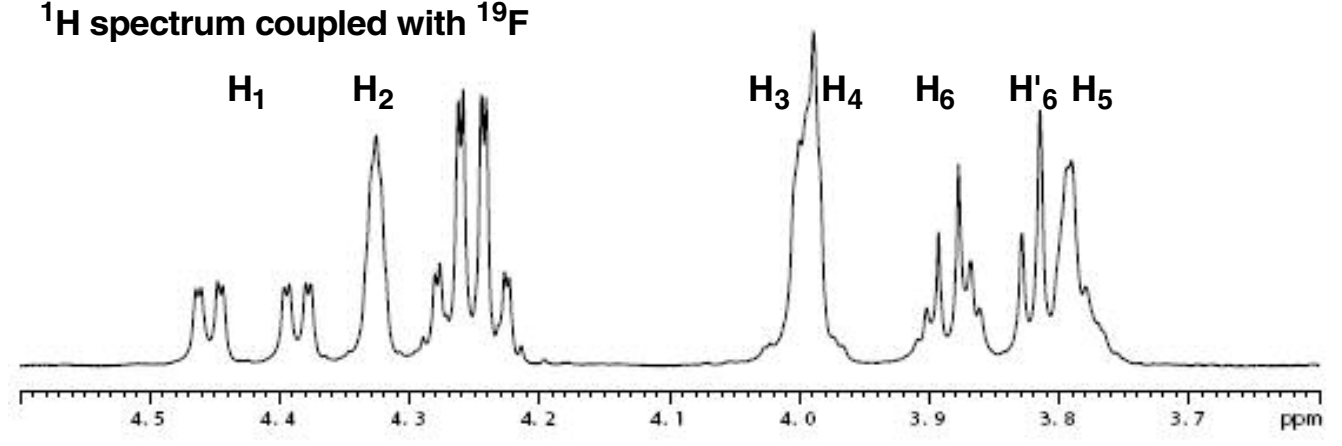

${ }^{1} \mathrm{H}$ NMR and COSY $\left(\mathrm{CDCl}_{3}, 400 \mathrm{Mhz}\right)$, compound 9

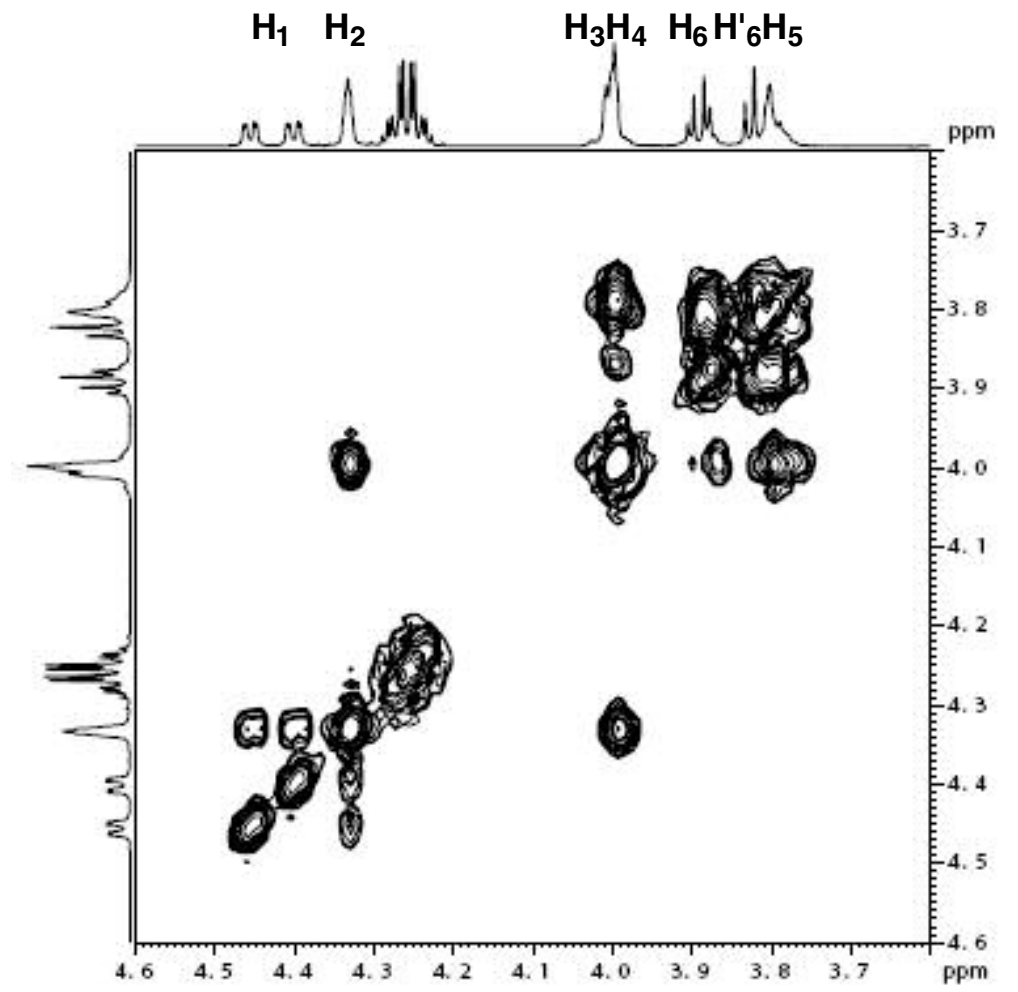


HOESY $\left(\mathrm{CDCl}_{3}, 400 \mathrm{Mhz}\right)$, compound 9

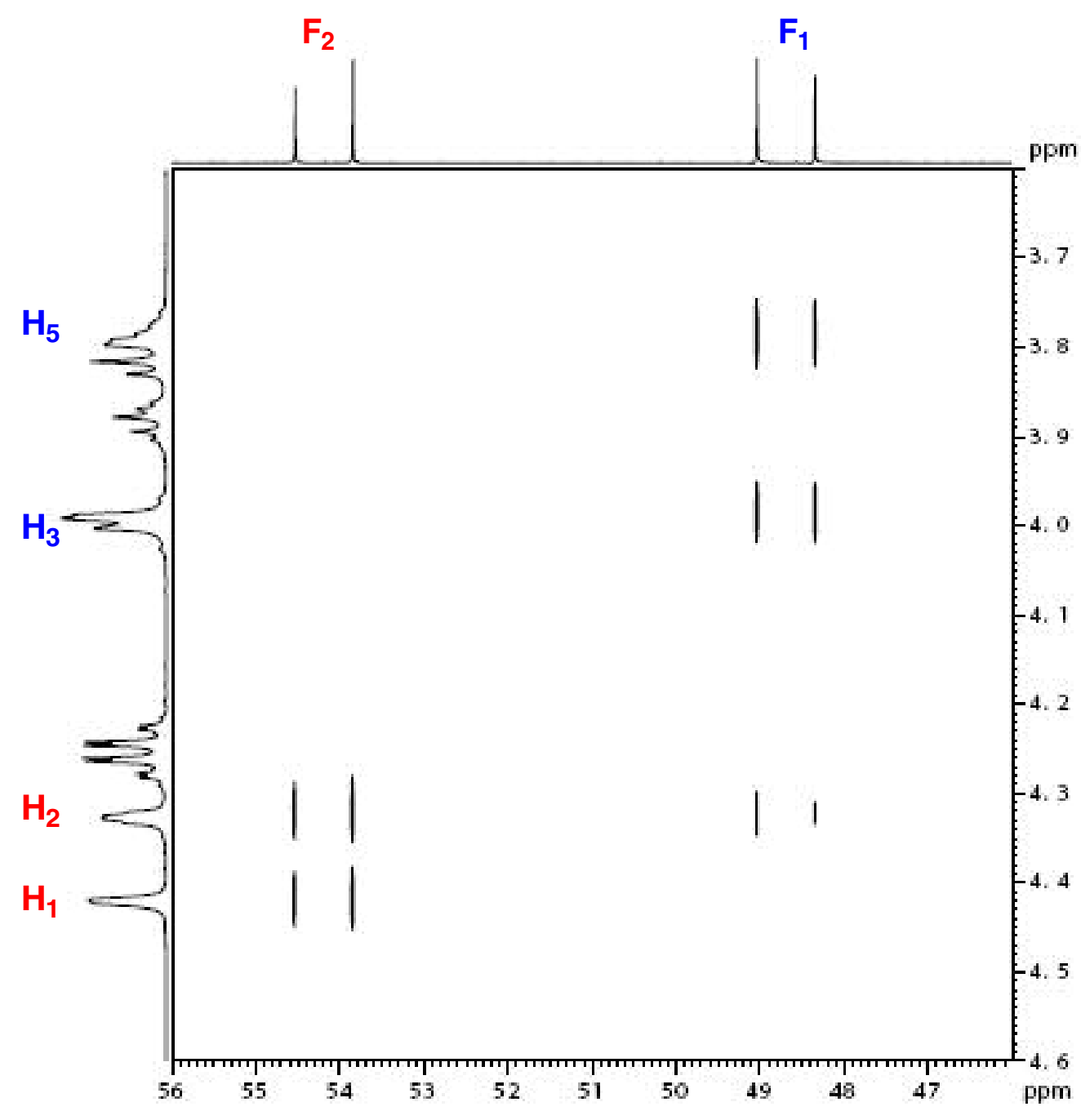

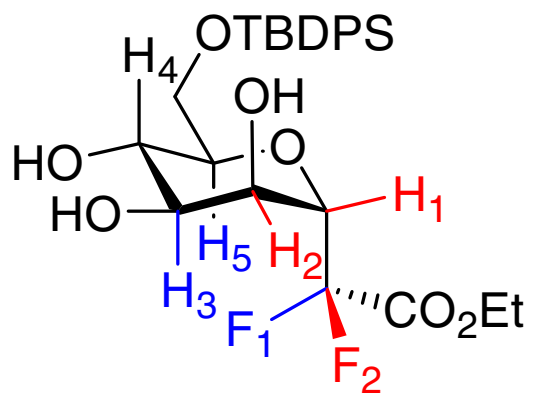

9

$\alpha$-Mannoside configuration

$>{ }^{4} \mathrm{C}_{1}$ Chair conformation

$>$ Exo/anti-type conformation of the $\mathrm{C}_{1}-\mathrm{CF}_{2}$ bond 
${ }^{13} \mathrm{C}$ NMR $\left(\mathrm{CDCl}_{3}\right)$, compound 9

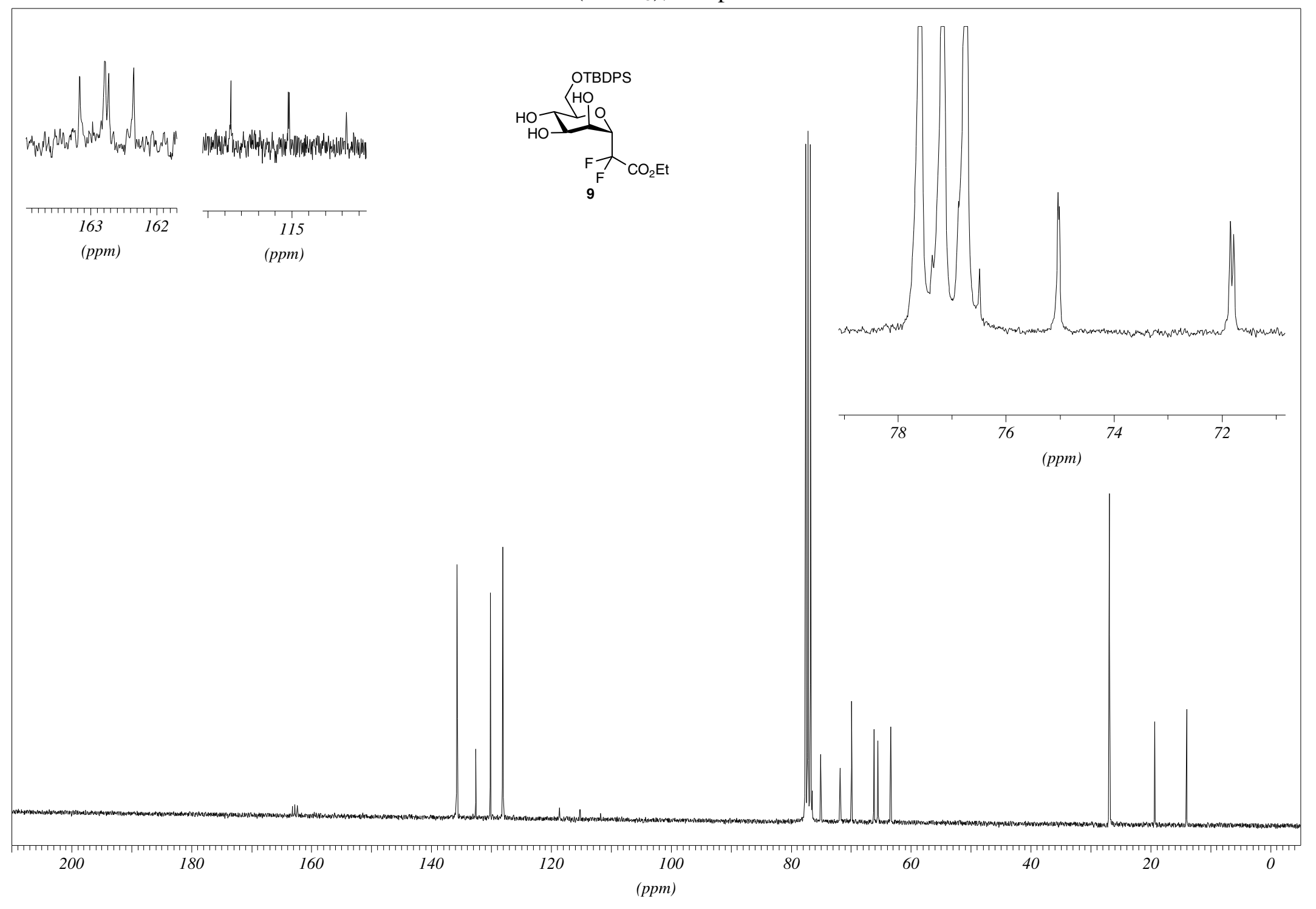


${ }^{13}$ C NMR DEPT $135\left(\mathrm{CDCl}_{3}\right)$, compound 9

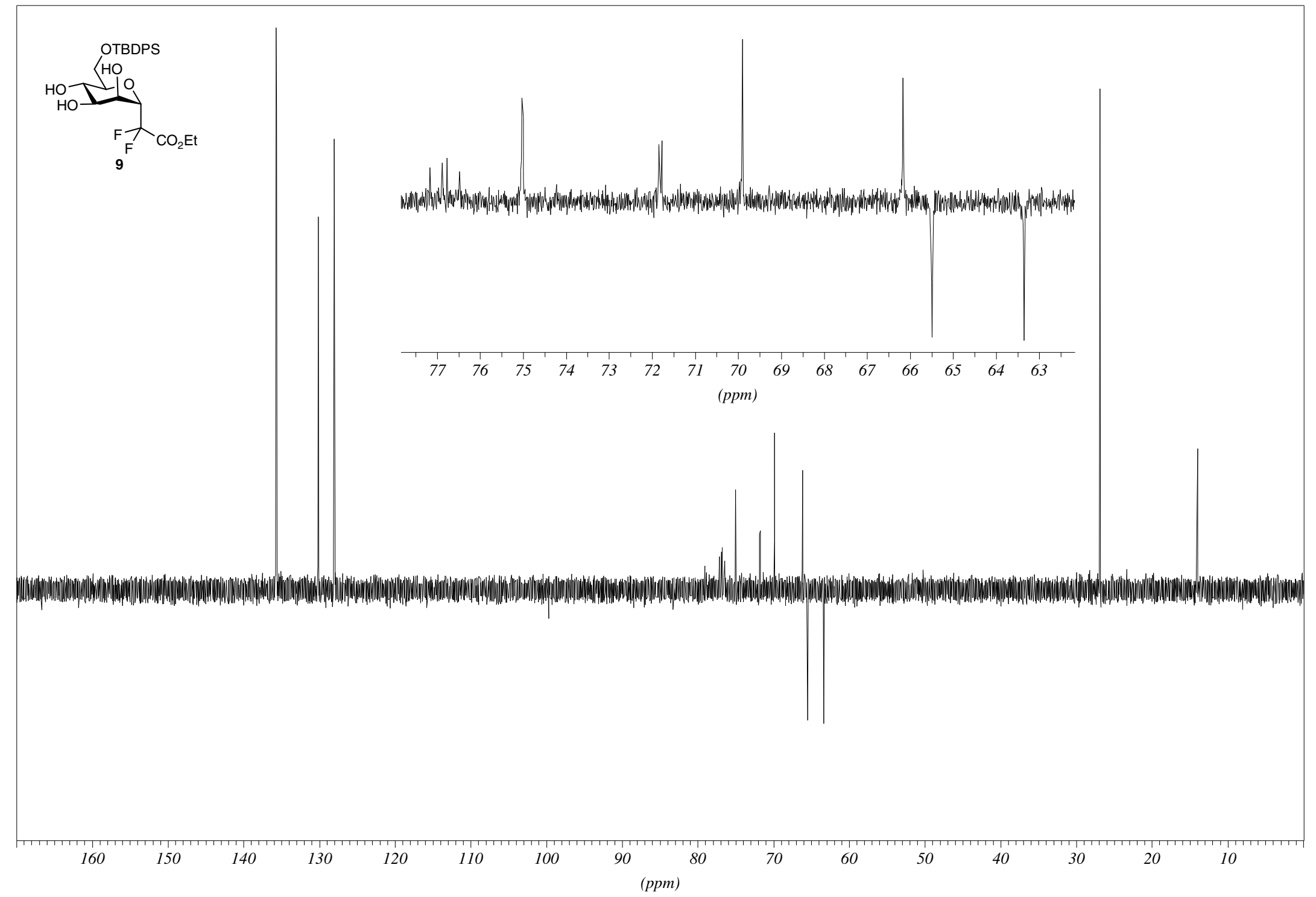


${ }^{13} \mathrm{C} \mathrm{NMR}\left(\mathrm{CDCl}_{3}, 400 \mathrm{Mhz}\right)$, compound 9

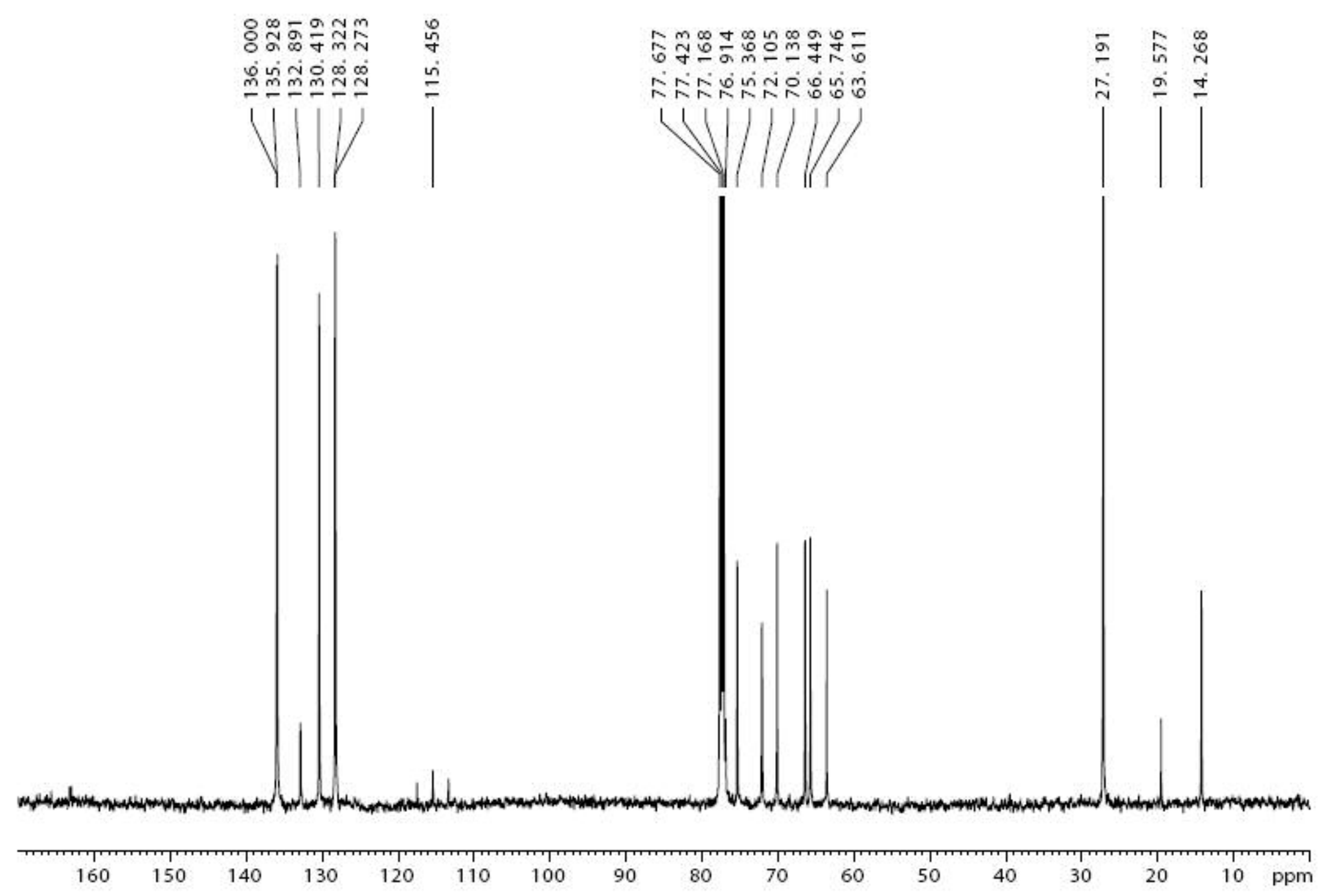




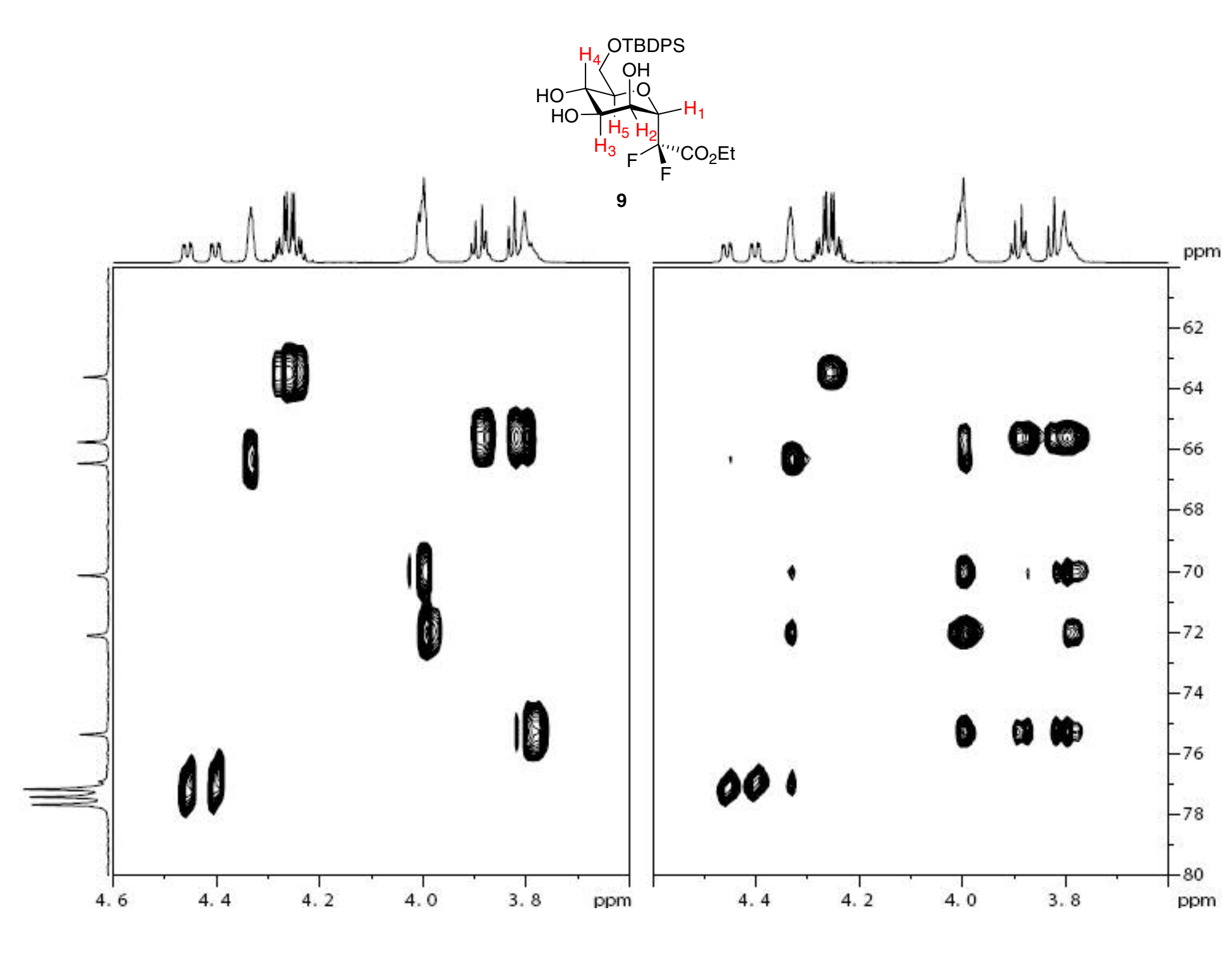


${ }^{1} \mathrm{H}$ NMR $\left(\mathrm{CDCl}_{3}\right)$, compound $\mathbf{1 2}$

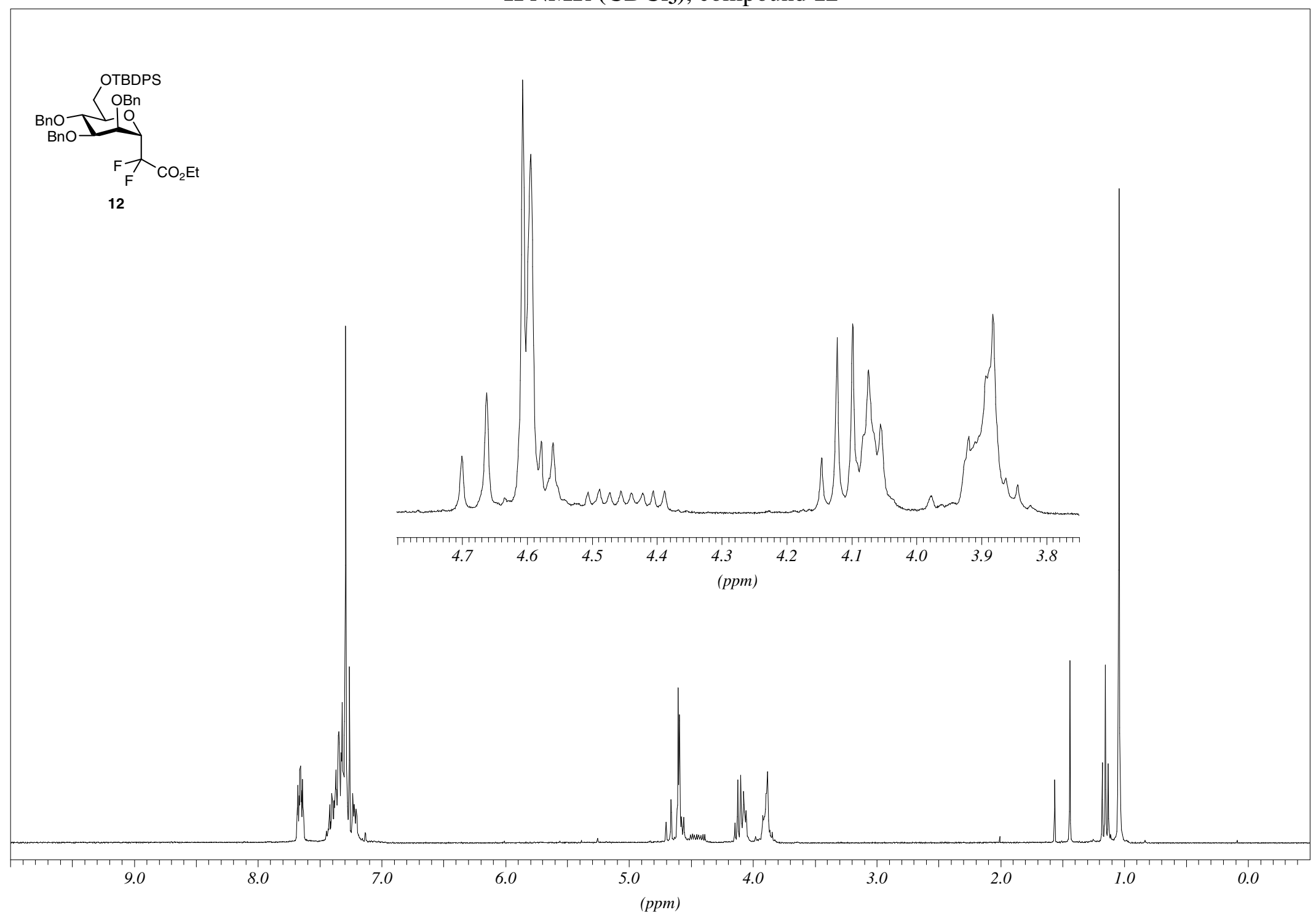


${ }^{19}$ F NMR $\left(\mathrm{CDCl}_{3}\right)$, compound 12

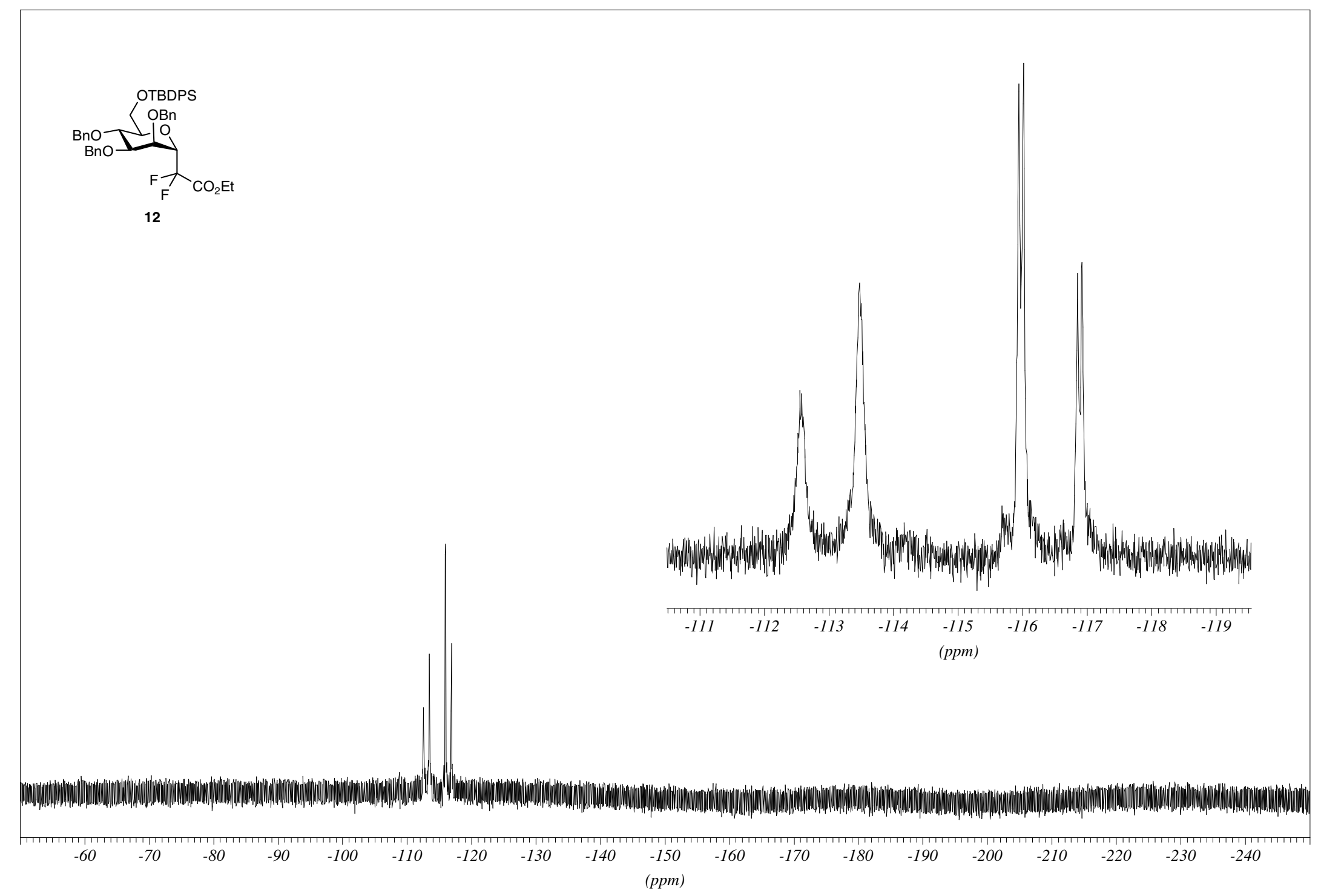


${ }^{13} \mathrm{C} \mathrm{NMR}\left(\mathrm{CDCl}_{3}\right)$, compound 12

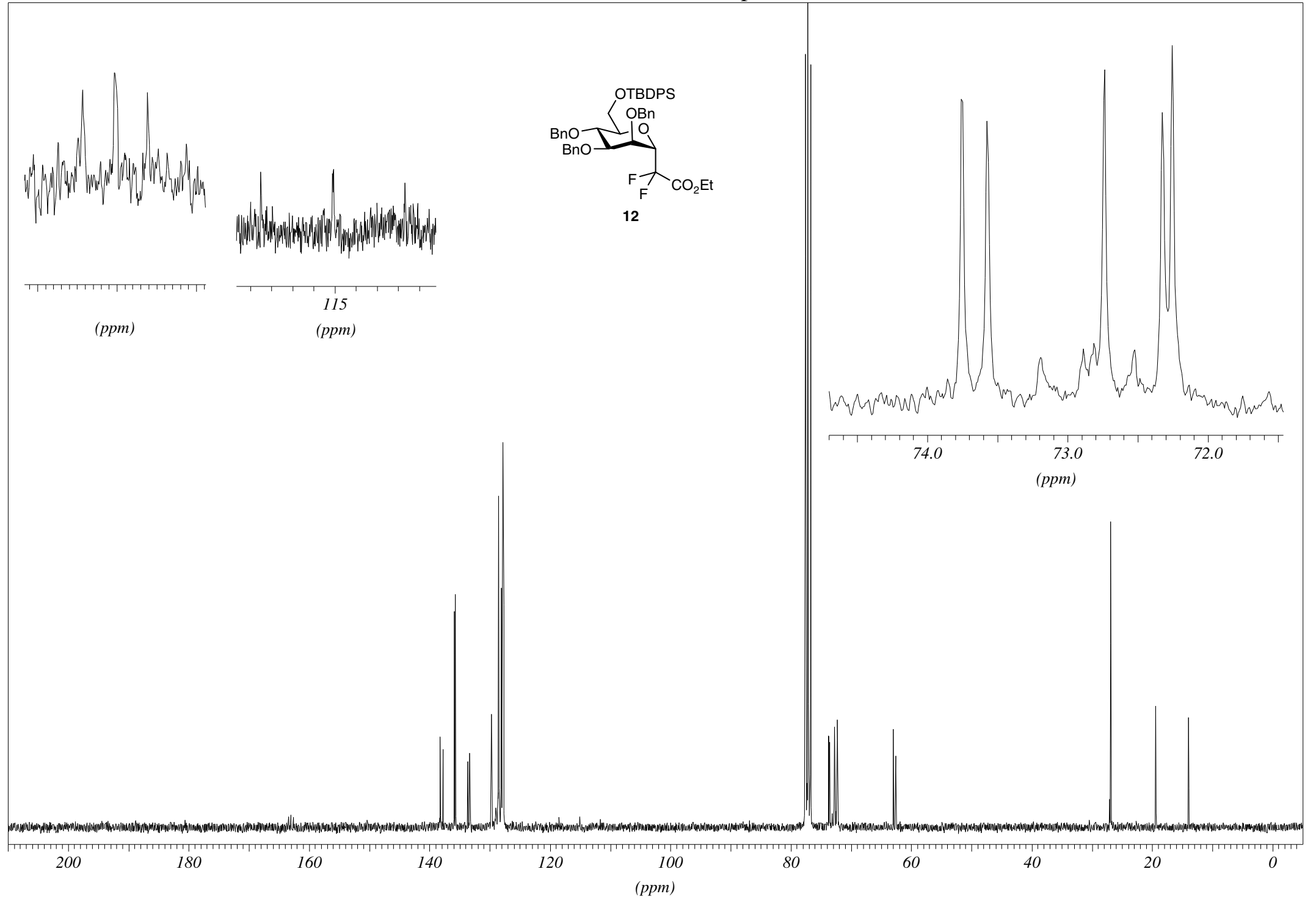


${ }^{1} \mathrm{H}$ NMR $\left(\mathrm{CDCl}_{3}\right)$, compound $\mathbf{1 3}$

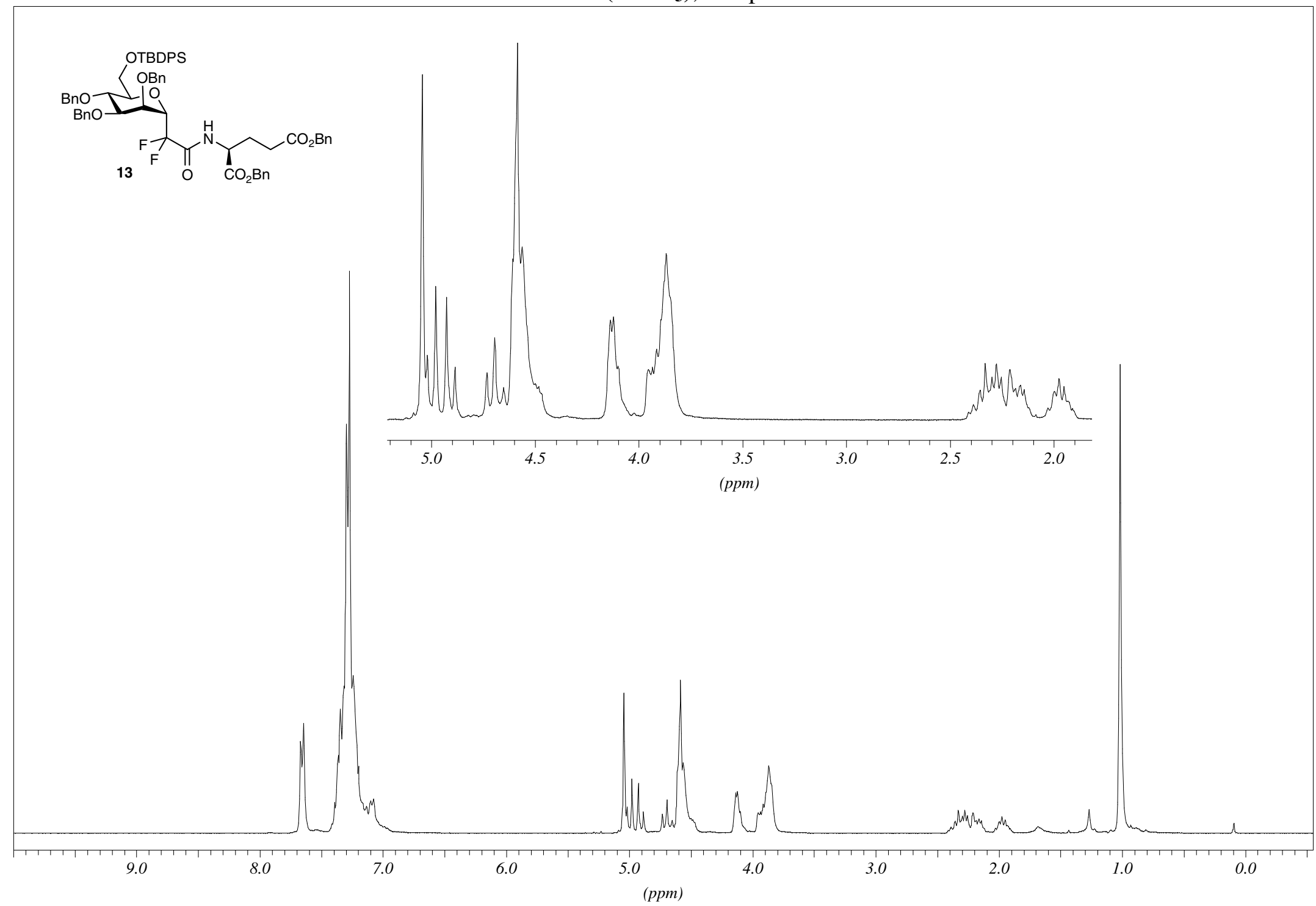




\section{${ }^{19}$ F NMR $\left(\mathrm{CDCl}_{3}\right)$, compound 13}

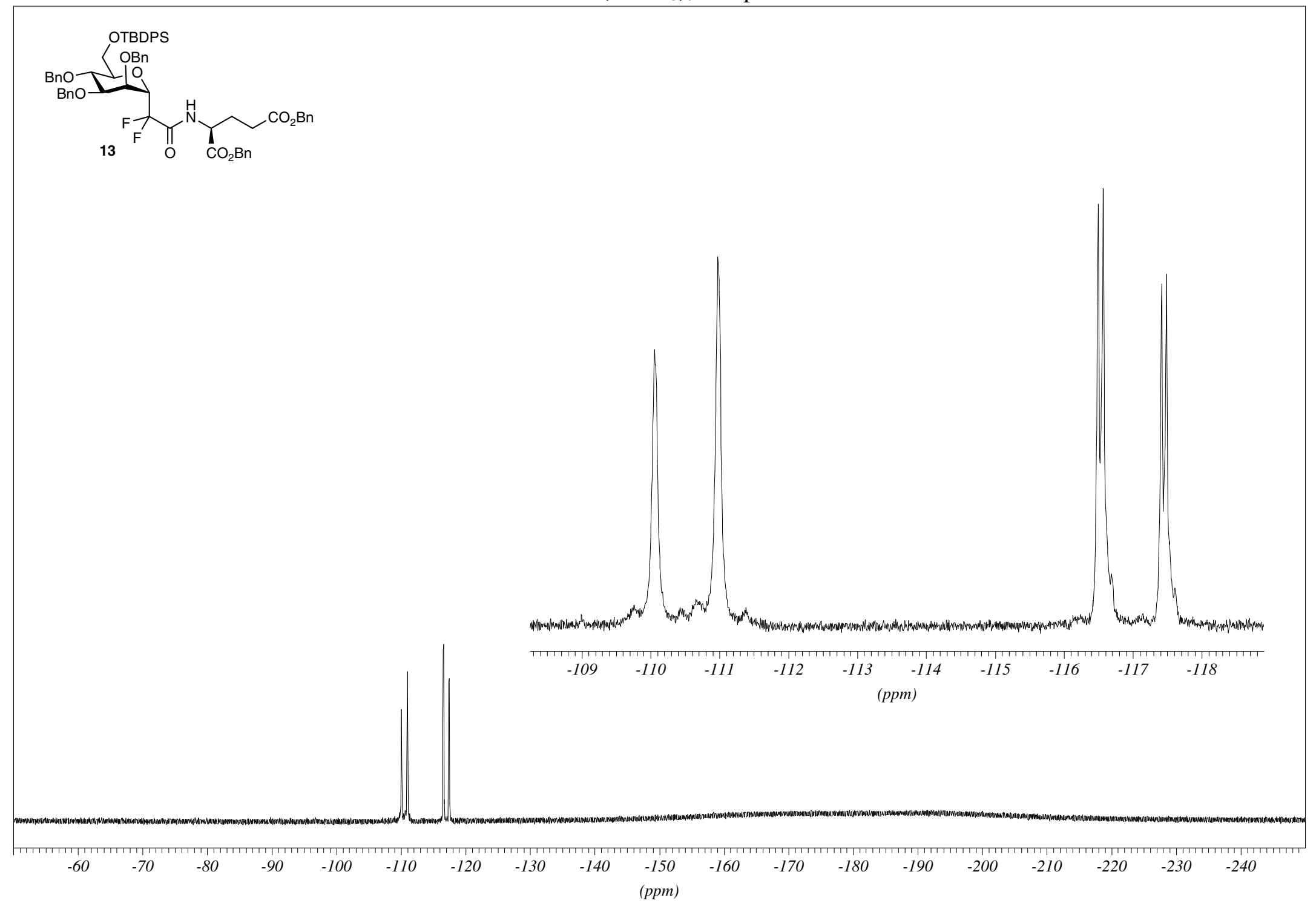


${ }^{13} \mathrm{C} \mathrm{NMR}\left(\mathrm{CDCl}_{3}\right)$, compound 13

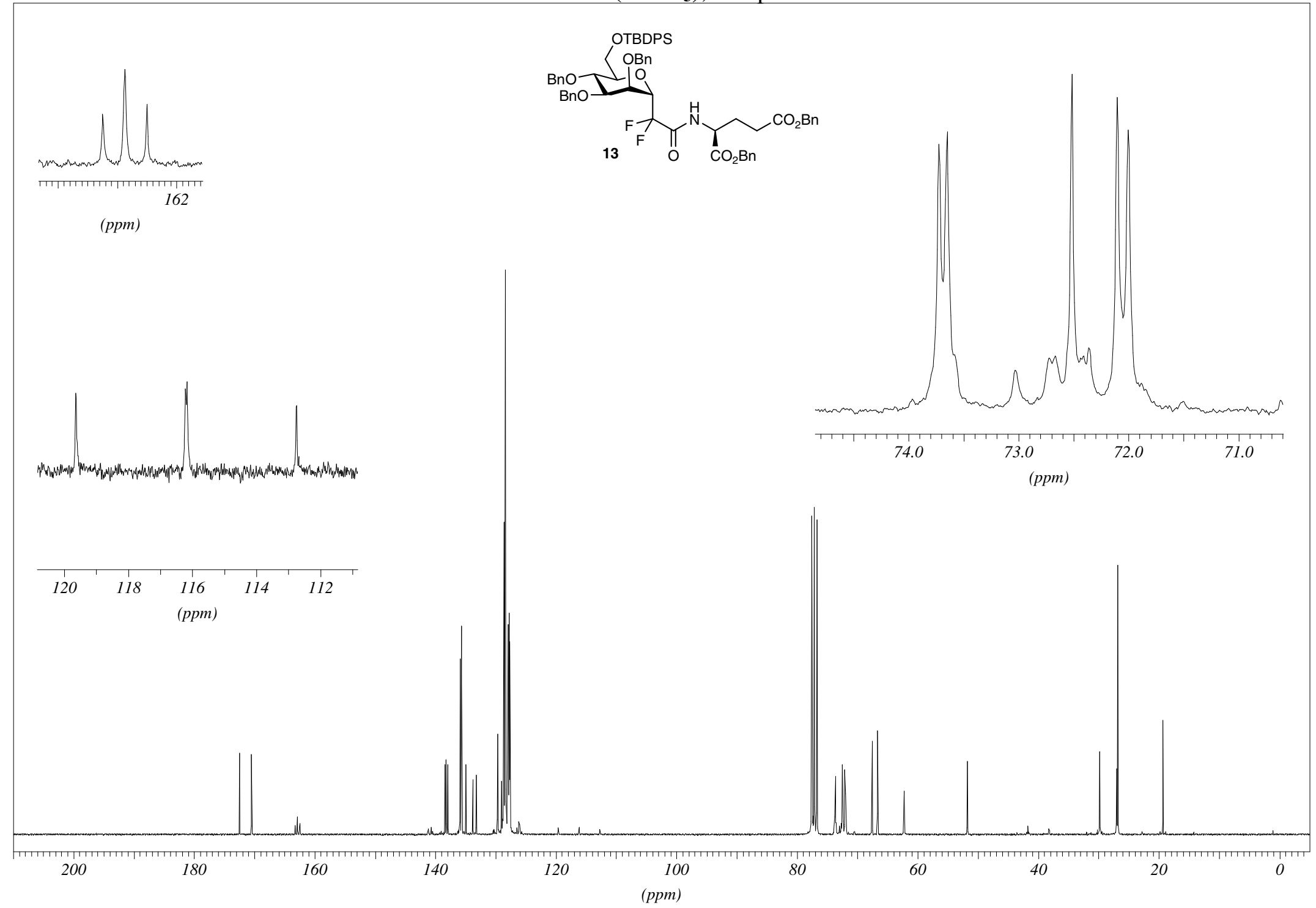


${ }^{13} \mathrm{C}$ NMR DEPT $135\left(\mathrm{CDCl}_{3}\right)$, compound 13

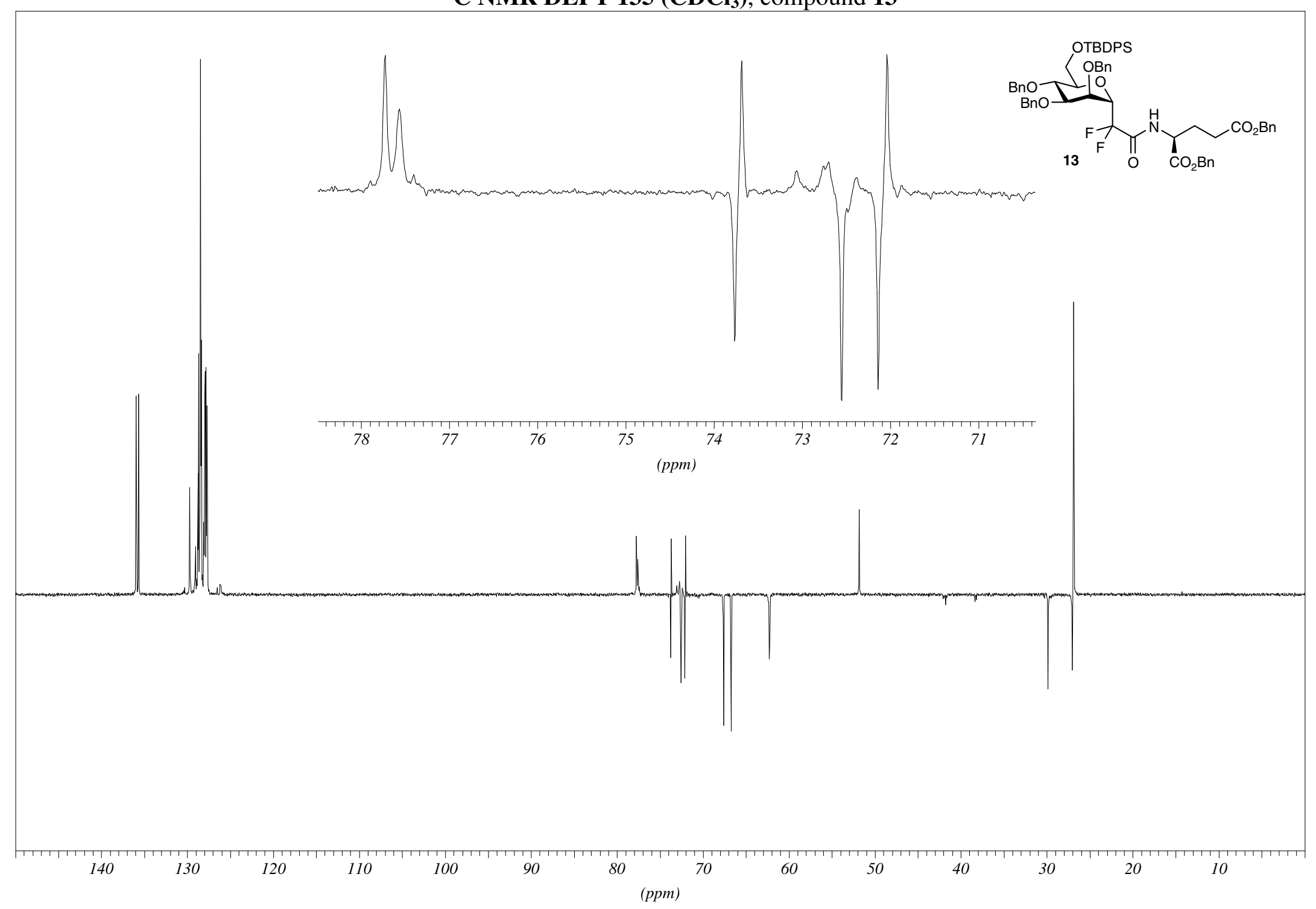


${ }^{1} \mathrm{H}$ NMR $\left(\mathrm{CDCl}_{3}\right)$, compound 14

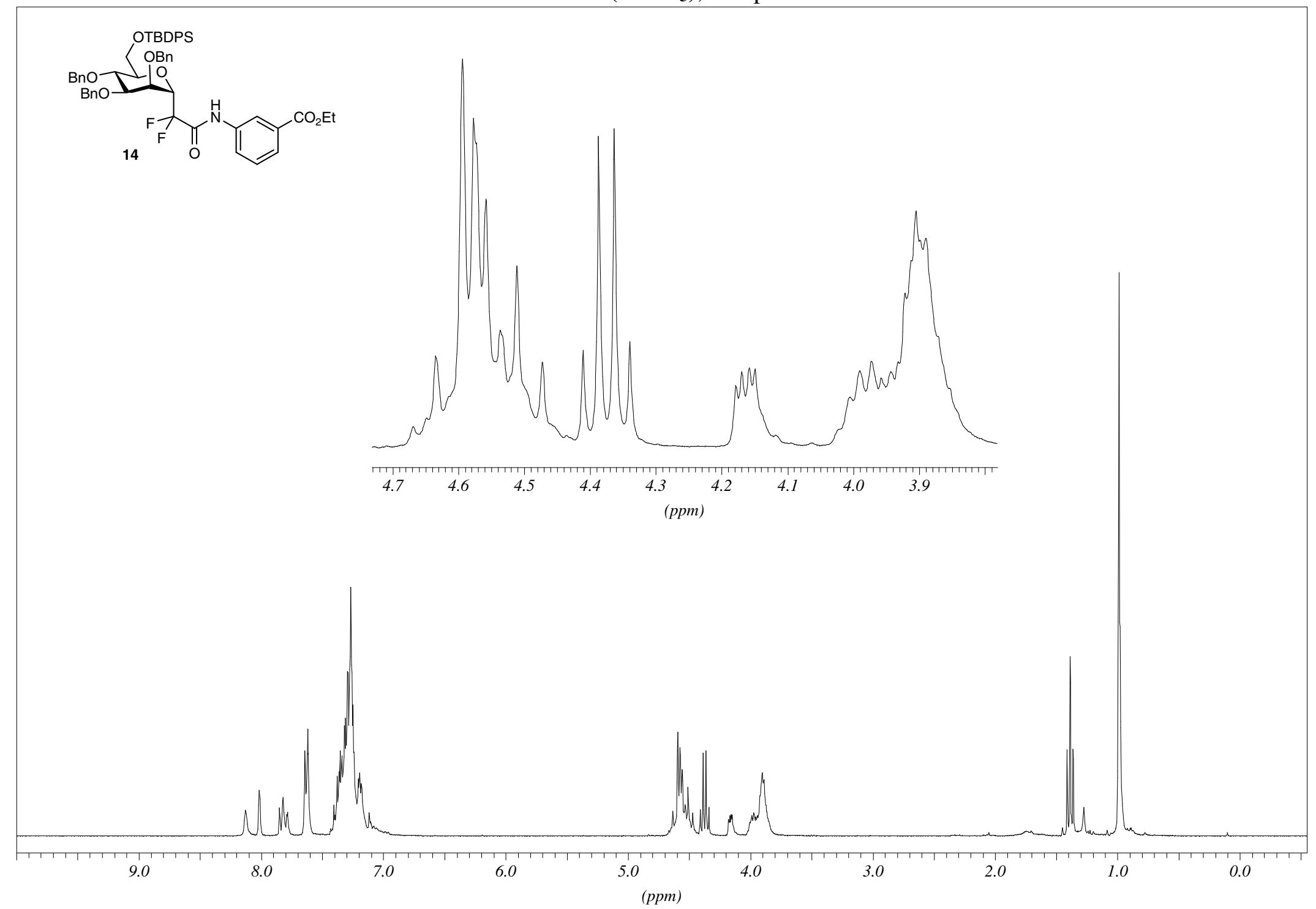


${ }^{19}$ F NMR $\left(\mathrm{CDCl}_{3}\right)$, compound 14

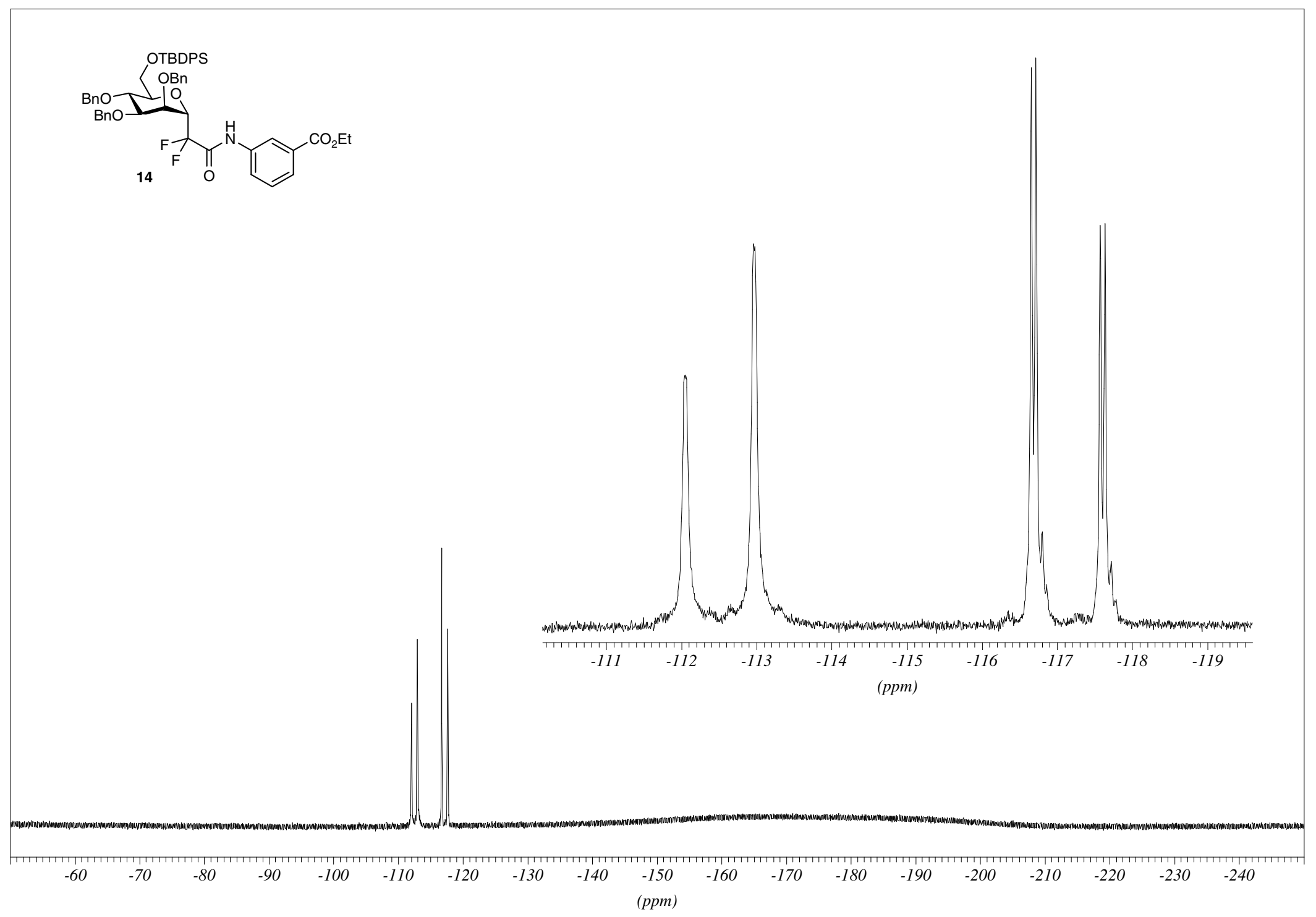


${ }^{13} \mathrm{C}$ NMR $\left(\mathrm{CDCl}_{3}\right)$, compound 14

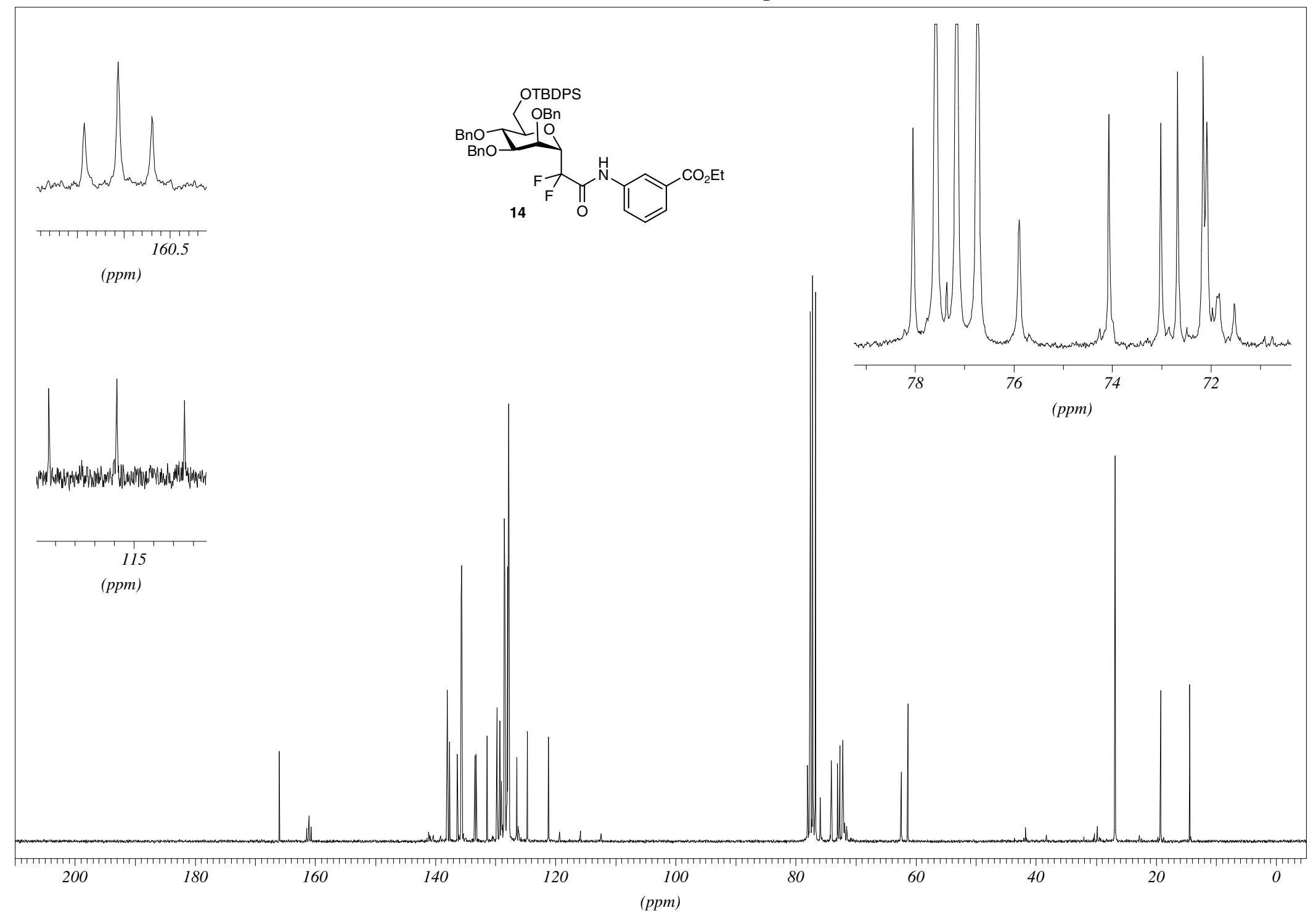

S50 
${ }^{13}$ C NMR DEPT $135\left(\mathrm{CDCl}_{3}\right)$, compound 14

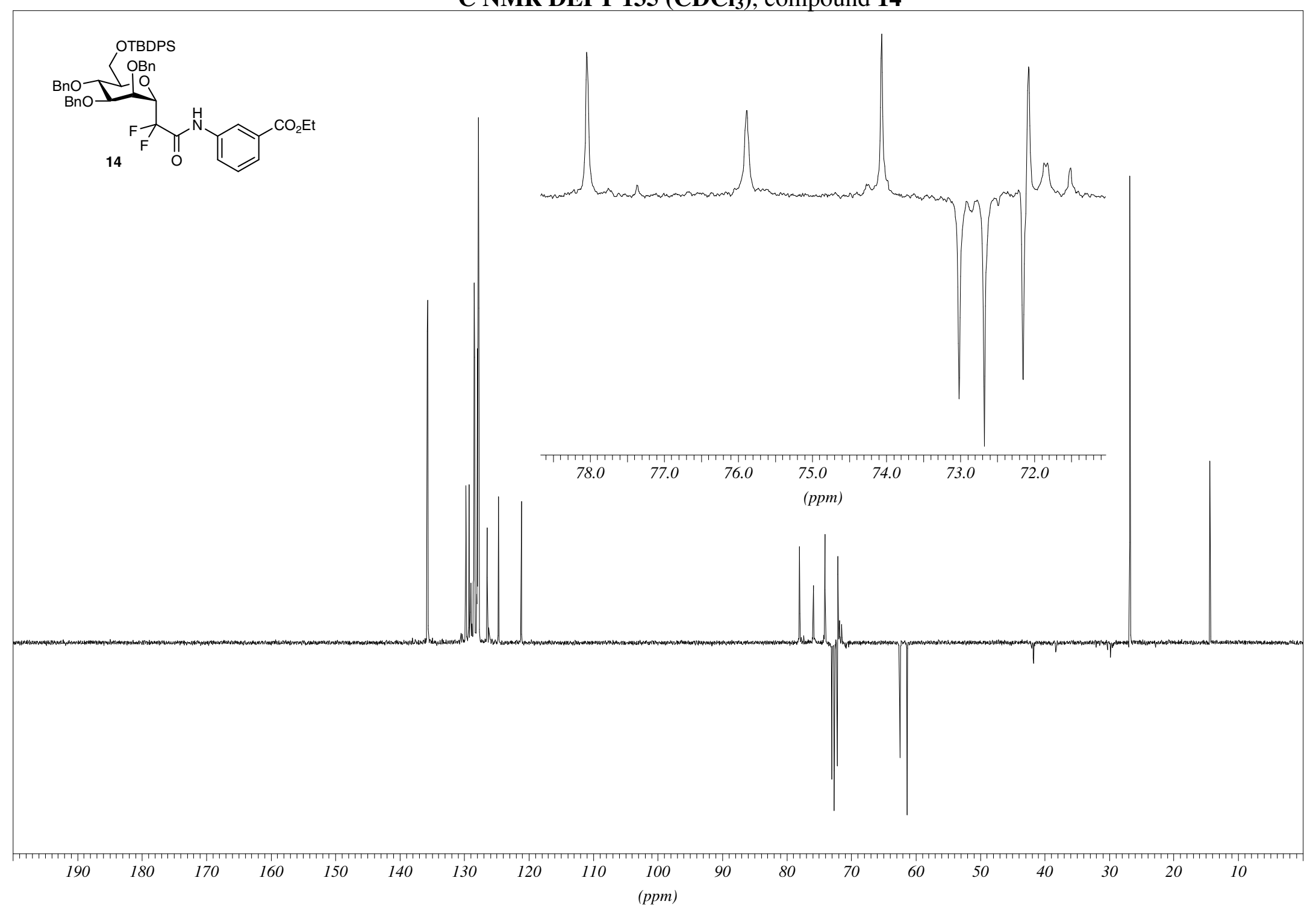


${ }^{1} \mathrm{H}$ NMR $\left(\mathrm{D}_{2} \mathrm{O}\right)$, compound $\alpha-3 \mathbf{a}$

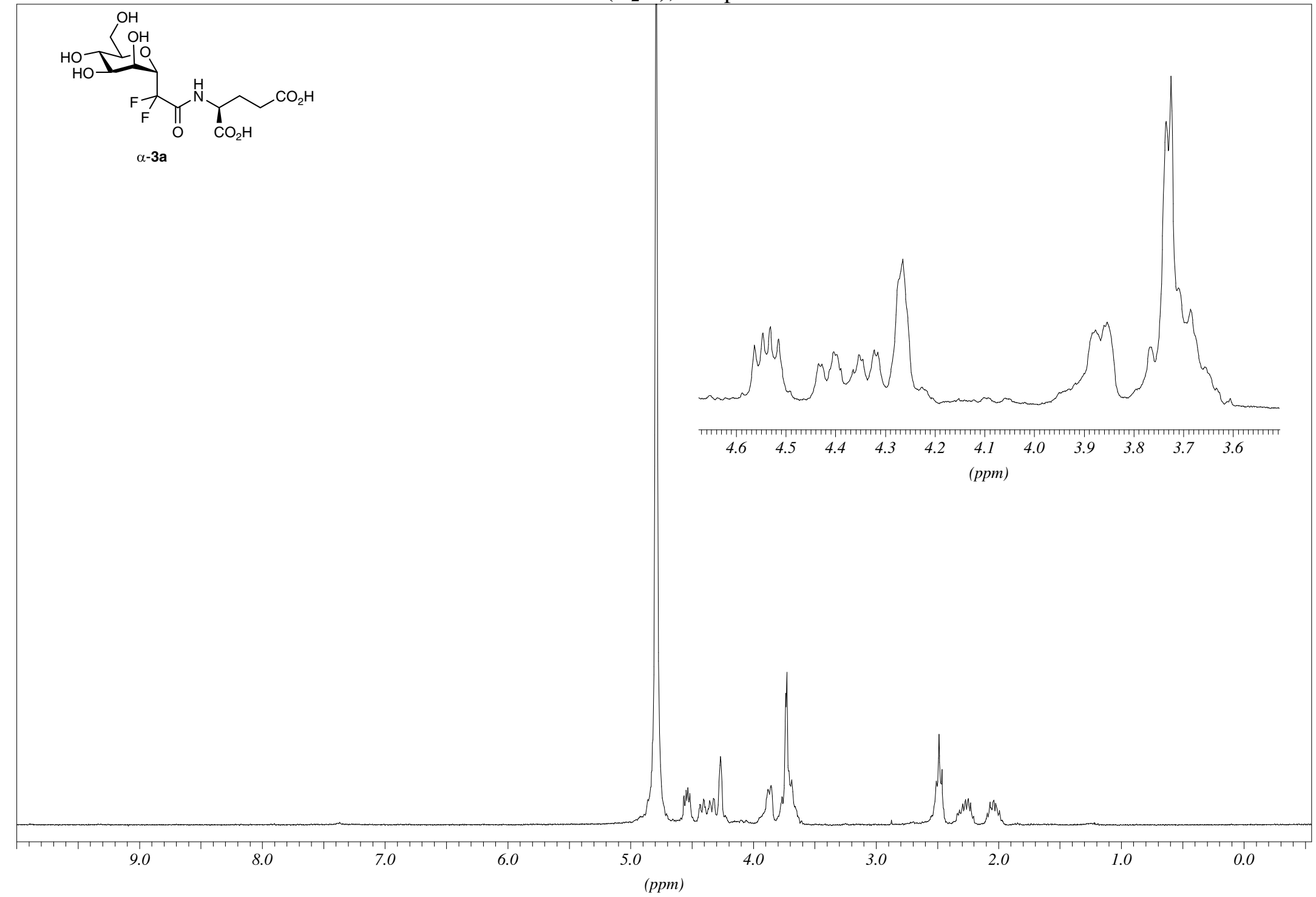


${ }^{19}$ F NMR $\left(\mathrm{D}_{2} \mathrm{O}\right)$, compound $\alpha-3 \mathrm{a}$

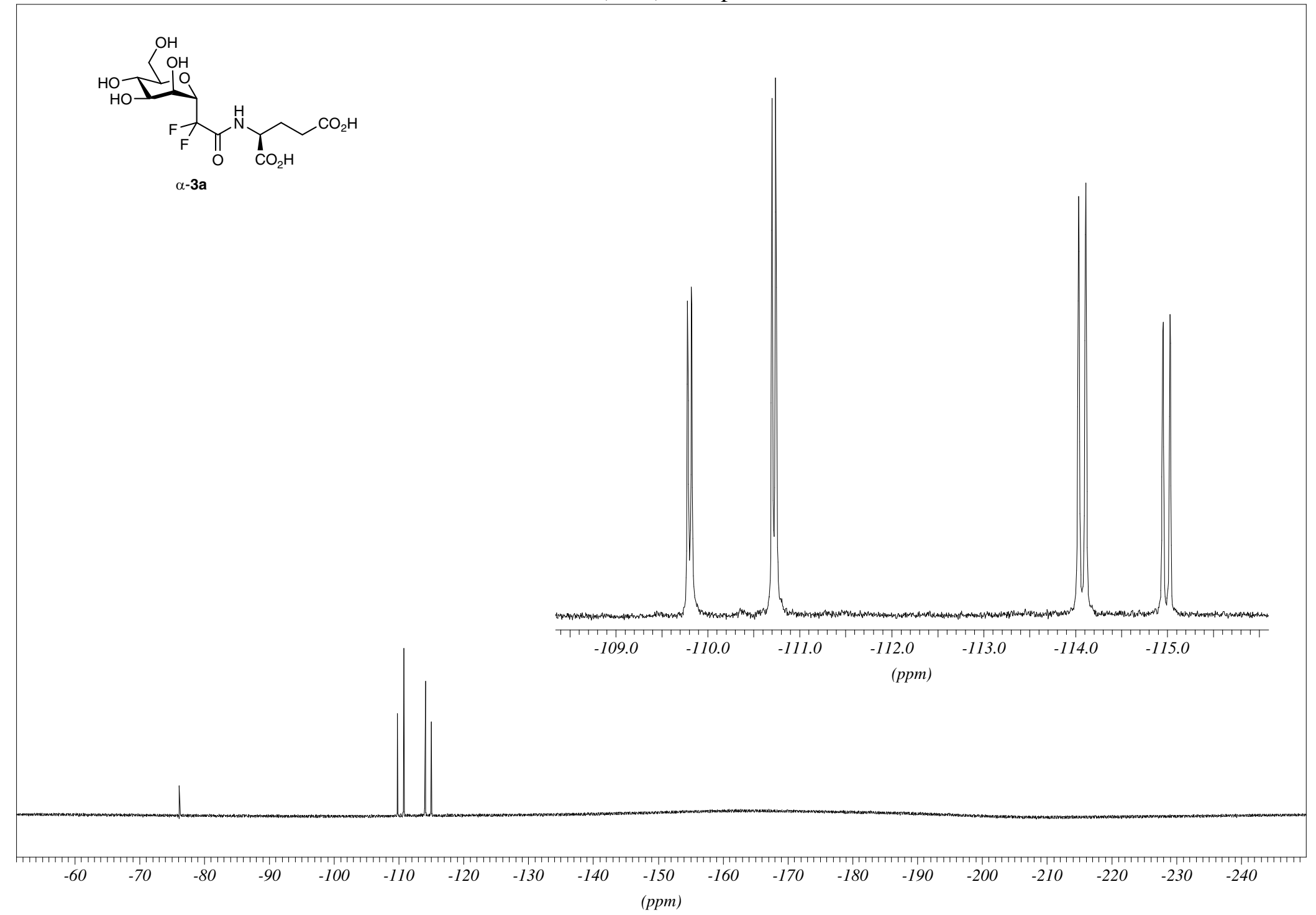


${ }^{13} \mathrm{C}$ NMR $\left(\mathrm{D}_{2} \mathrm{O}\right)$, compound $\alpha-3 \mathbf{a}$

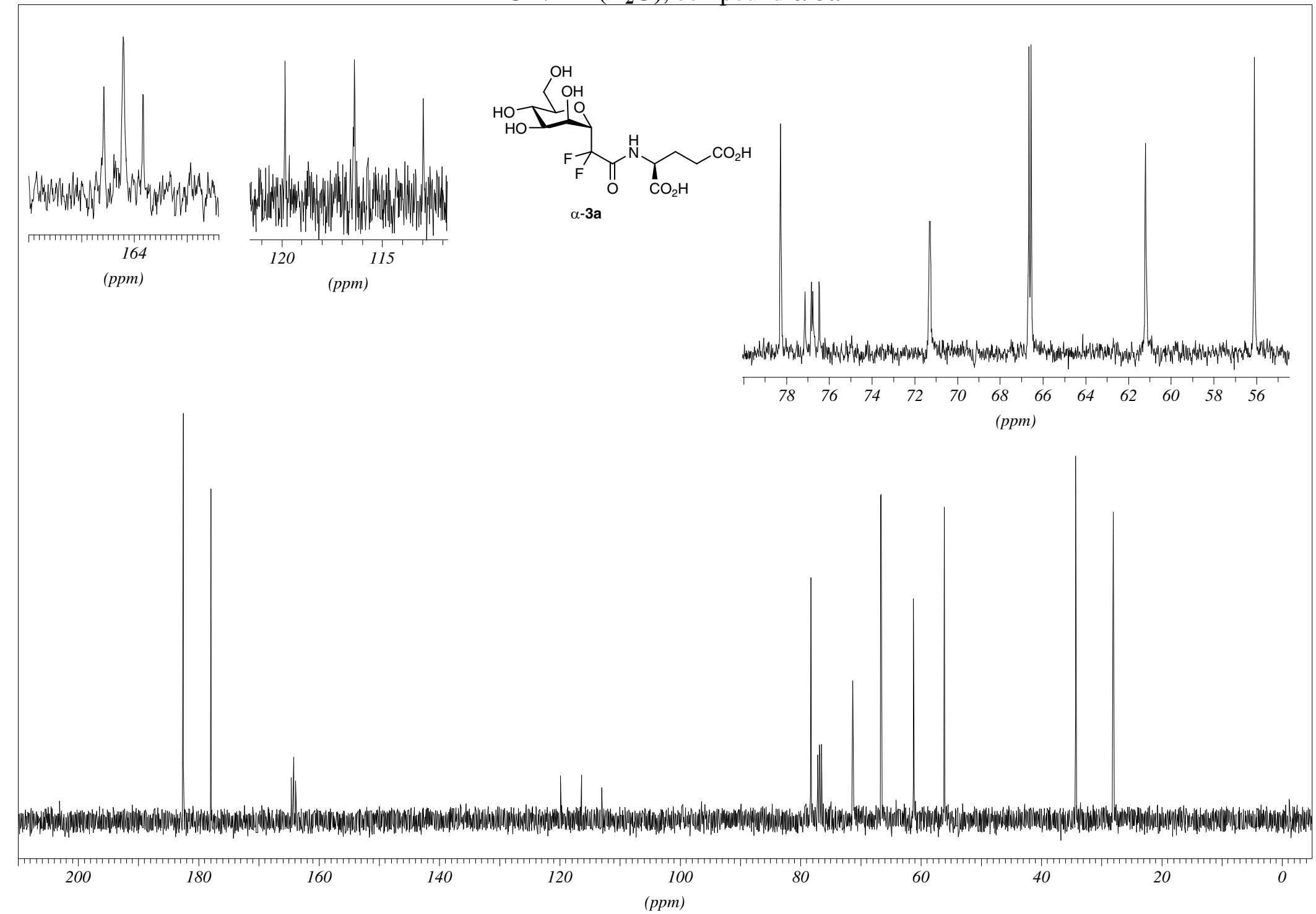


${ }^{1} \mathbf{H}$ NMR $\left(D_{2} \mathbf{O}\right)$, compound $\alpha-3 b$

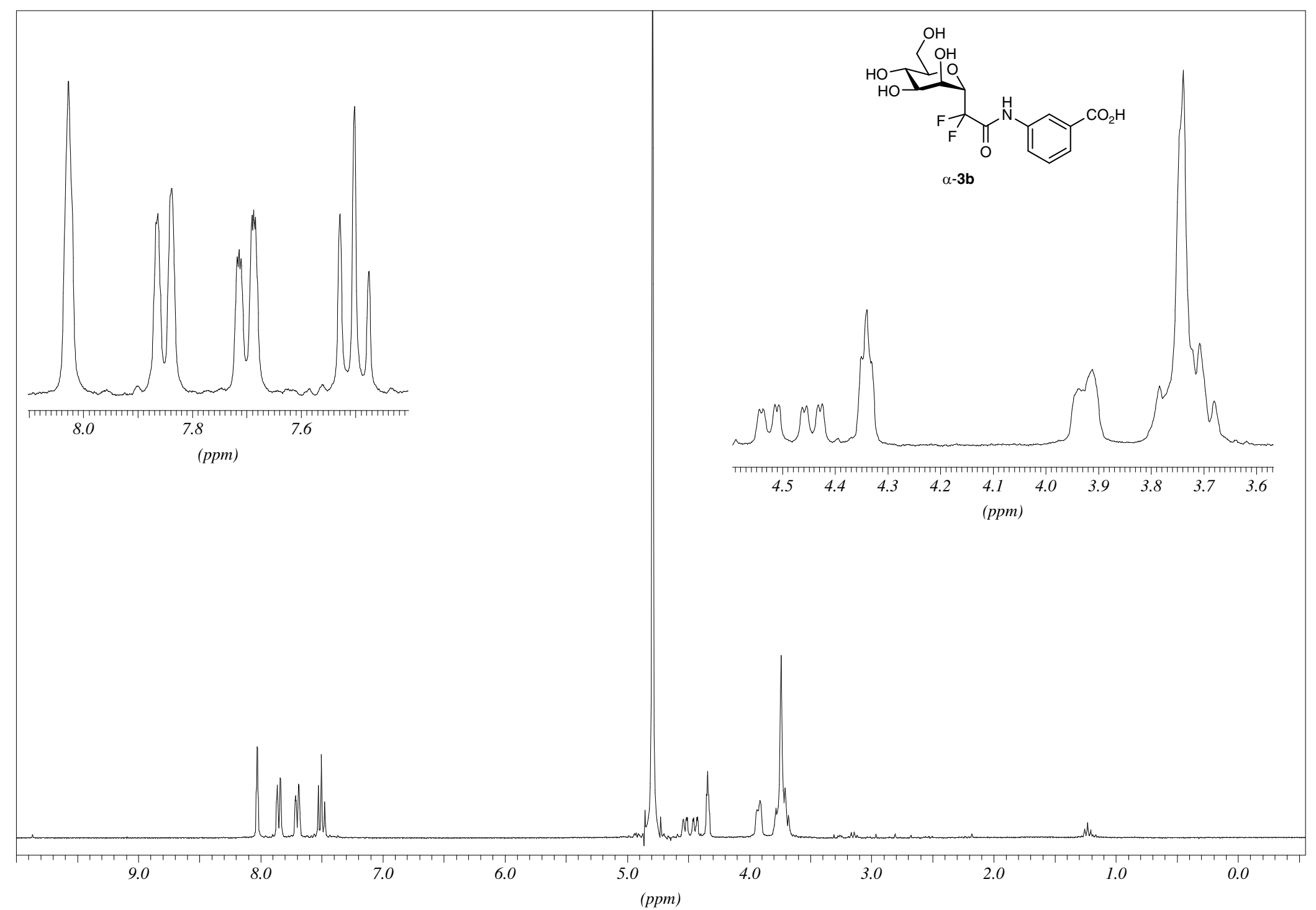


${ }^{19}$ F NMR $\left(\mathrm{D}_{2} \mathrm{O}\right)$, compound $\alpha-3 \mathrm{~b}$

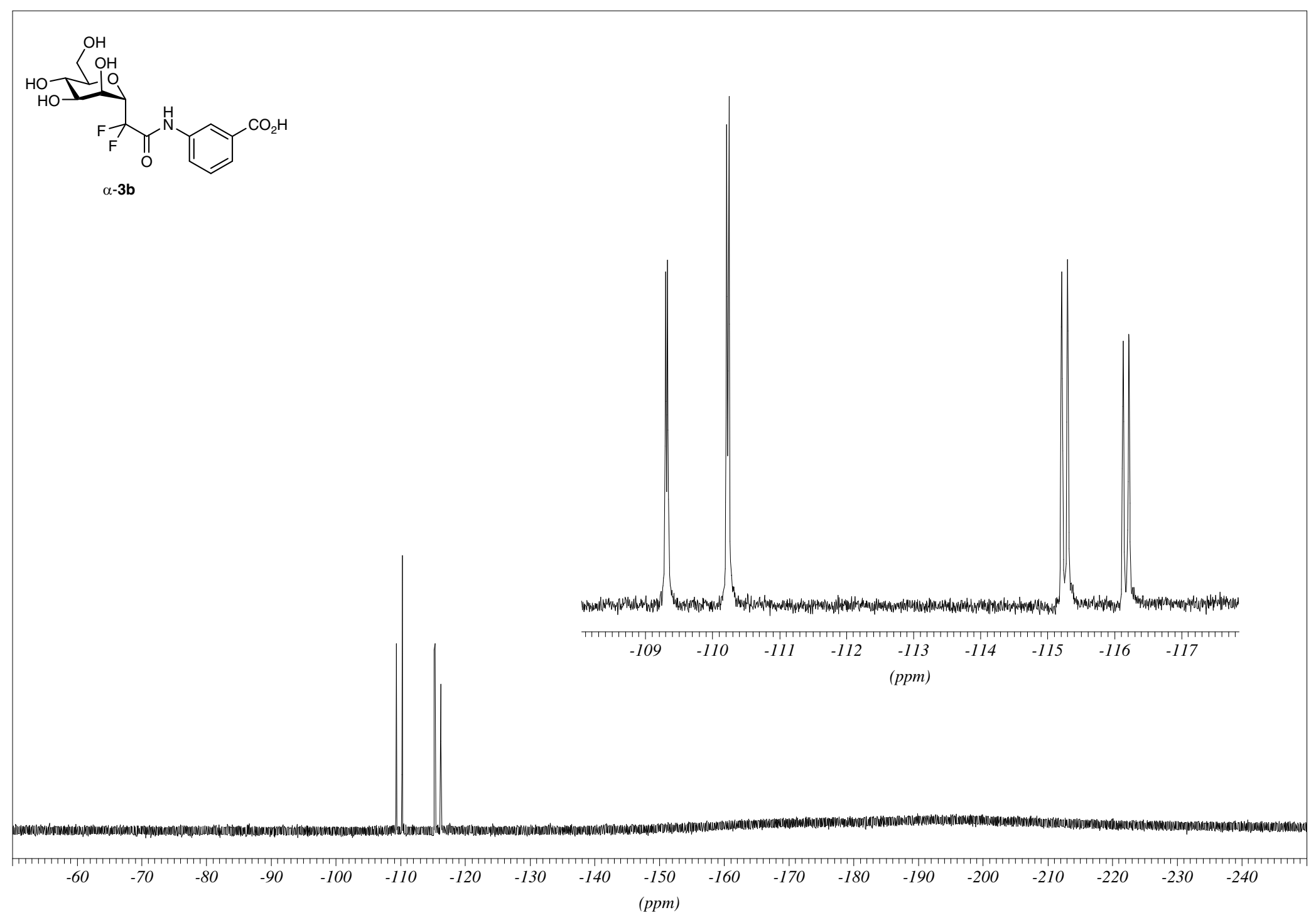


${ }^{13} \mathrm{C}$ NMR $\left(\mathrm{D}_{2} \mathrm{O}\right)$, compound $\alpha-3 \mathrm{~b}$

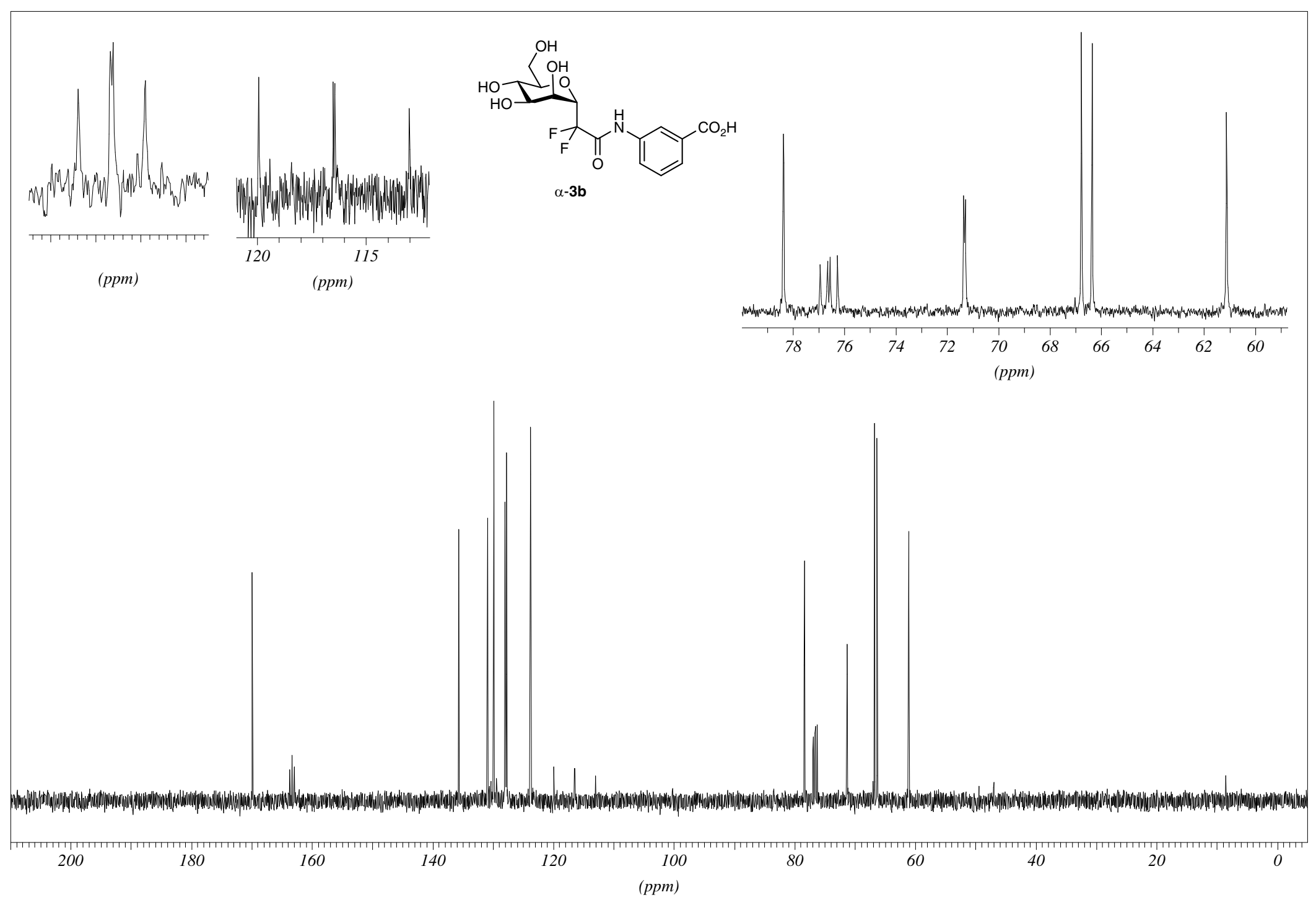

S57 
${ }^{13}$ C NMR DEPT $135\left(D_{2} O\right)$, compound $\alpha-3 b$

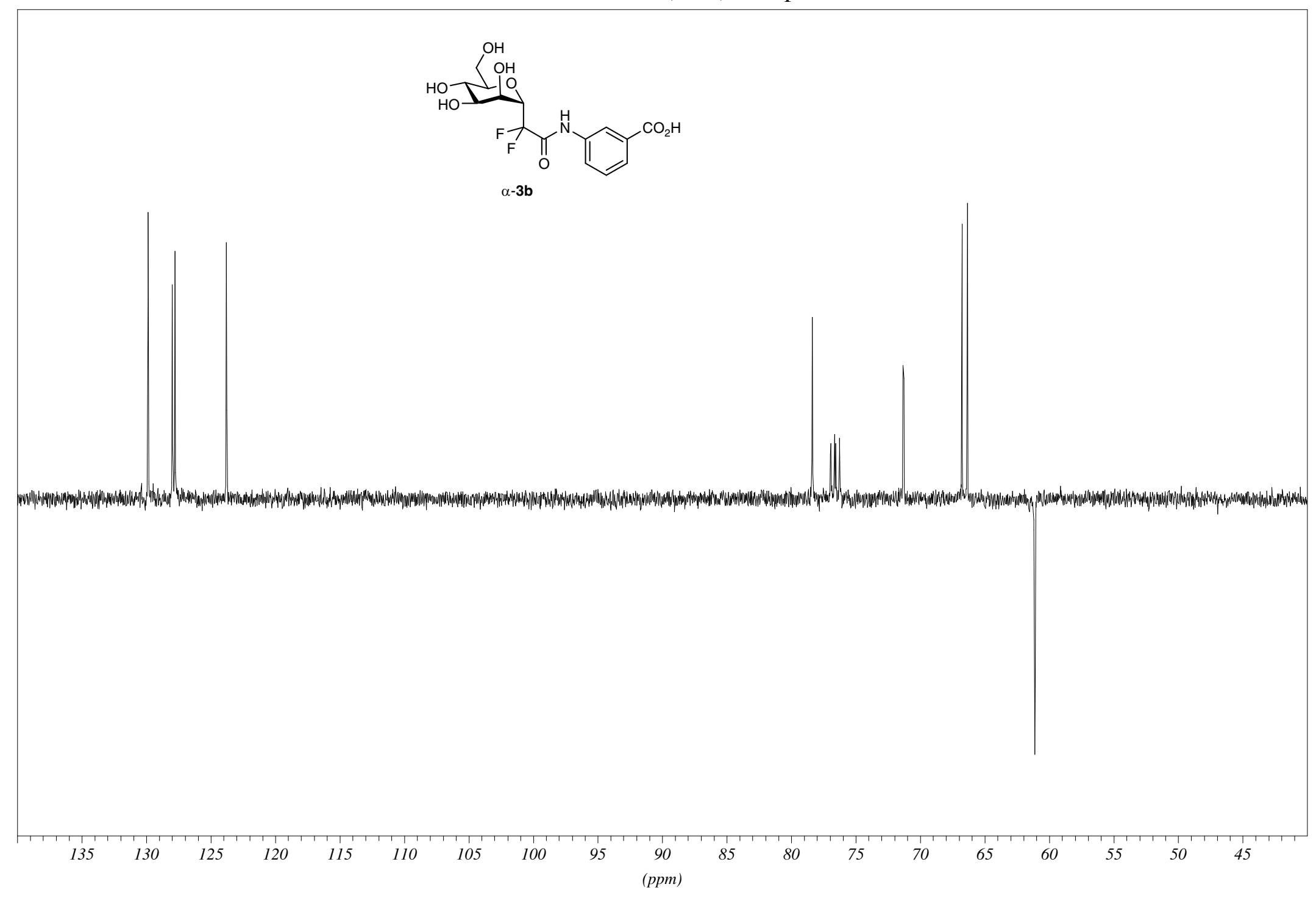

